\title{
BEHAVIORAL GENETICS: THE SCIENCE OF ANTISOCIAL BEHAVIOR
}

\author{
LAURA A. BAKER, ${ }^{*}$ SERENA BEZDJIAN, ${ }^{* *}$ AND ADRIAN RAINE***
}

\section{INTRODUCTION}

Social scientists generally agree that a paradigm shift has occurred over the course of the last three decades of research in human behavior: the zeitgeist has moved away from a culturally centered, social learning model towards a more balanced perspective in which both genetic and environmental factors are understood to explain the wide variations observed in human behavior. This perspective now applies in the areas of mental health and illness, as well as across several domains of normal, varying psychological constructs, such as intelligence, personality, interests, and attitudes. The study of antisocial behavior is no exception to this paradigm shift. There is now abundant evidence that both genetic and environmental influences-and probably their interaction-are of major importance in explaining individual differences in antisocial behavior, including differences in criminal behavior.

Evidence for a genetic basis of antisocial behavior stems from several different lines of research. First, behavioral genetic studies of twins and adoptees have demonstrated that heredity plays a role in antisocial behavior, including various forms of aggression and criminality, by finding greater concordance for such behavior in genetically related individuals compared to nonrelatives living in the same environment. Second, various correlates of antisocial behavior, including personality factors such as impulsivity, sensationseeking, risk-taking, and callous-unemotional traits, are known to be at least partly genetically influenced. Third, psychiatric outcomes related to antisocial behavior, including antisocial personality disorder, gambling, and substance use

\footnotetext{
Copyright ( 92006 by Laura A. Baker, Serena Bezdjian, and Adrian Raine

This Article is also available at http://law.duke.edu/journals/lcp.

* Associate Professor of Psychology, Department of Psychology, University of Southern California.

** Graduate Student, Department of Psychology, Unversity of Southern California.

*** Robert G. Wright Professor of Psychology, Department of Psychology, University of Southern California.

The authors wish to thank the twins and their families for their participation in the USC Twin Study and the twin project staff for assistance in data collection and scoring. The authors and the USC Twin Study were supported by grants to Laura A. Baker from NIMH (R01 MH58354), to Serena Bezdjian from NIMH (Predoctoral Fellowship Award F31 MH068953) and to Adrian Raine from NIMH (Independent Scientist Award K02 MH01114-01).
} 
and abuse, have also been investigated in genetically informative designs, and each of these has demonstrated significant genetic influence.

This paper summarizes the heritability of each of these aspects or correlates of antisocial behavior and discusses research attempting to unpack the genetic and environmental "black boxes" involved in antisocial behavior, including studies investigating the influence of both biological and social risk factors and how they might be mediated by genetic and environmental factors. Examples of biological risk factors could be neurotransmitters, physiological arousal, frontal lobe function, and hormones, while social risk factors would include socioeconomic status, peer characteristics, and parental monitoring and discipline. Biological risk factors may not necessarily be entirely genetically based, and social risk factors may not be purely environmental in origin; this highlights the complexity of the relationships between risk factors and antisocial behavior.

This paper also reports studies that have identified specific genetic associations with antisocial behavior. Yet genetic predispositions, though important, are more deleterious in the presence of adverse environments. This view dovetails with other biosocial theories of antisocial behavior in which the effects of biological risk factors have been found to be moderated by social circumstances. An overarching biosocial model of antisocial behavior is presented here, along with a discussion of a few key findings that demonstrate interactions of social and biological factors in the development of antisocial behavior.

Finally, this paper considers the implications of behavioral genetic research on antisocial behavior for understanding individual responsibility. No individual's behavior can ever be explained entirely, either in terms of genetic predispositions or in terms of cumulative experiences, and an explanation of an individual's behavior, even if it were complete, would not necessarily excuse that behavior. Even with increasing understanding of the genetic bases of human behavior, a cautious approach is warranted either in making inferences about a given individual or in considering changes to the legal system that might now take a defendant's experiences and disposition into account.

II

\section{RESEARCH DESIGNS IN BEHAVIORAL GENETICS}

Before delving into the evidence for genetic and environmental influences on antisocial behavior, it may be helpful to review the basic research designs in behavioral genetics: (1) classical genetic designs, which infer global genetic and environmental influences through analyzing resemblance among family members of varying degrees of genetic and environmental relatedness, including twins, nuclear families, and adoptive families; and (2) quantitative trait loci (QTL) designs, in which specific DNA sequences are identified and tested for functional significance or associations with such complex traits as antisocial behavior. Although classical approaches are considered more 
"global" in that they broadly determine whether genes are important and estimate the magnitude of genetic influences, the QTL designs provide a more "molecular approach" because they attempt to specify more precisely what underlying genetic and biological mechanisms might increase an individual's risk of engaging in antisocial behavior.

\section{A. Classical Genetic Designs}

The traditional approach to studying genetic and environmental influences on human behavior does not involve any direct examination of DNA, but infers observed individual differences (phenotypic variance) in a given trait, such as antisocial behavior through examination of patterns of resemblance among individuals who are related genetically, environmentally, or both. ${ }^{1}$ The general approach partitions the phenotypic variance $\left(\mathrm{V}_{\mathrm{p}}\right)$ into genetic $\left(\mathrm{V}_{\mathrm{G}}\right)$ and environmental $\left(\mathrm{V}_{\mathrm{E}}\right)$ factors. Environmental influences are typically divided further into those shared by family members $\left(\mathrm{V}_{\mathrm{Es}}\right)$ and those not shared but unique to each individual in the family $\left(\mathrm{V}_{\mathrm{Ens}}\right)$. Different types of genetic influences can also be distinguished; some are due to additive effects of genes at various loci $\left(\mathrm{V}_{\mathrm{A}}\right)$, while others are the result of nonadditive genetic effects due to dominance (interactions between different forms of a gene at one locus) $\left(\mathrm{V}_{\mathrm{D}}\right)$ and epistasis (interactions between genes at various loci) $\left(\mathrm{V}_{\mathrm{I}}\right)$. The distinction between shared and nonshared environments is almost always made in classical genetic designs, although additive and nonadditive genetic effects are not always separated. Studies rarely attempt to estimate epistatic genetic effects, since their total contribution to observable variance is widely thought to be small even when such effects are present. These components of variance add to the total variance in a linear fashion:

$$
\mathrm{V}_{\mathrm{P}}=\mathrm{V}_{\mathrm{G}}+\mathrm{V}_{\mathrm{E}}=\mathrm{V}_{\mathrm{A}}+\mathrm{V}_{\mathrm{D}}+\mathrm{V}_{\mathrm{I}}+\mathrm{V}_{\mathrm{Es}}+\mathrm{V}_{\text {Ens }} \text { (eq. } 1 \text { ). }
$$

Dividing both sides of the equation by $\mathrm{V}_{\mathrm{P}}$ yields proportional effects of each class of influence, indicating the relative amount of phenotypic variance explained by various types of genetic and environmental factors:

$$
1=h^{2}+e^{2}=a^{2}+d^{2}+i^{2}+e_{s}^{2}+e_{n s}^{2} \text { (eq. 2). }
$$

The relative effect of genetic factors on phenotypic differences among individuals $\left(\mathrm{h}^{2}\right)$ is the heritability of the trait, while environmental influences $\left(\mathrm{e}^{2}\right)$ are the environmentality of the trait. When distinguishing among different types of genetic influence, it is possible to calculate broad-sense heritability $\left(h_{B}^{2}\right)$, which encompasses all genetic influences $\left(a^{2}+d^{2}+i^{2}\right)$, or narrow-sense

1. See generally Robert Plomin et al., BeHAVIORAl GeNETiCs 72-92 (4th ed. 2001) (reviewing basic structure of adoption and twin designs); Laura A. Baker, Methods for Understanding Genetic and Environmental Influences in Normal and Abnormal Personality, in DIFFERENTIATING NORMAL AND AbNoRmal Personality (S. Strack ed., 2006) (in press) (reviewing the major classical genetic designs as well as their assumptions, strengths, and weaknesses). 
heritability $\left(\mathrm{h}_{\mathrm{N}}^{2}\right)$, which reflects only additive effects $\left(\mathrm{a}^{2}\right){ }^{2}$ An illustration of these relative effects as portions of the total phenotypic variance for a given trait is provided in Figure 1, which also shows that the effects of measurement error may be taken into account as a separate component of variance.

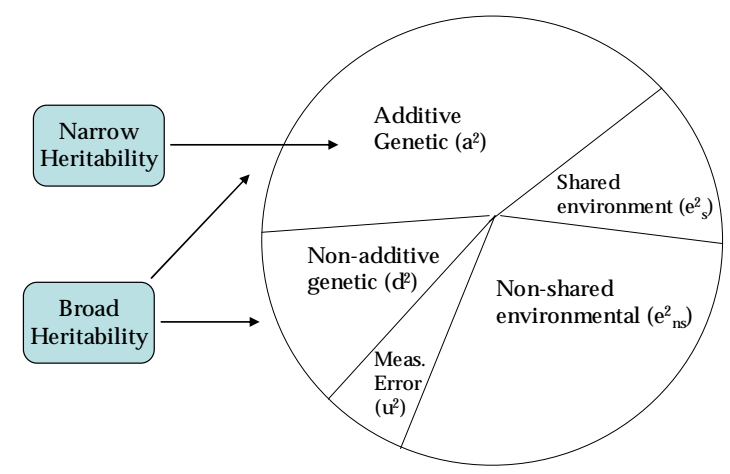

Figure 1: Components of Genetic and Environmental Variance

These effects might be estimated algebraically or through complex model-fitting algorithms on the basis of observed correlations (or covariances) among various pairs of relatives. A path diagram representing one given pair of relatives in a classical genetic design is shown in Figure 2.

2. Genes do not always act in a dominant or recessive fashion (such that one gene masks the effects of another gene). Instead, each gene at a given locus may contribute additively to the phenotype. Even when dominant genes are involved, however, additive effects can appear. 


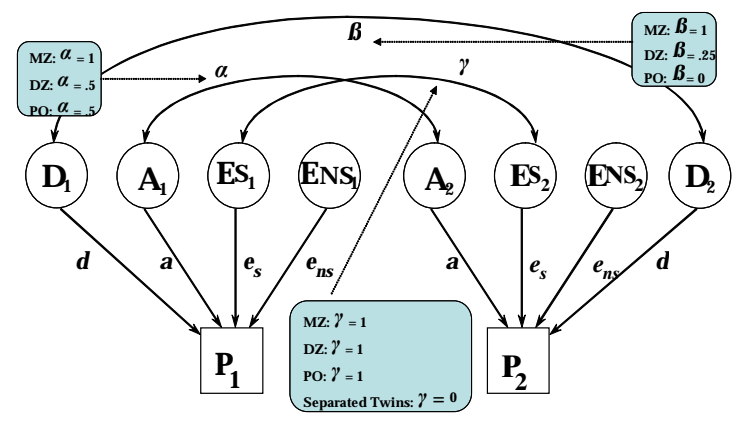

\section{Figure 2: Path Model of Covariance Between Two Relatives (P1 and P2)}

In twin studies, for example, monozygotic (MZ) twins share one hundred percent of their genetic material, while dizygotic (DZ) twins on average share only fifty percent of their genes. The expected correlations between co-twins (the two individuals in a given twin pair) may be derived from the model shown in Figure 2 as follows:

$$
\begin{aligned}
& r \mathrm{MZ}=\mathrm{a}^{2}+\mathrm{e}^{2} \mathrm{~s} \quad \text { (eq. 3) } \\
& r \mathrm{DZ}=1 / 2 \mathrm{a}^{2}+\mathrm{e}^{2} \mathrm{~s} \text { (eq. 4) }
\end{aligned}
$$

Assuming that both types of twins share environments to the same degree-a reasonable assumption, given their contemporaneous age and developmentany increased similarity in MZ compared to DZ twins is taken to imply the importance of genetic factors on the trait under study. In particular, narrowsense heritability $\left(\mathrm{a}^{2}\right)$ may be calculated from the correlations between $\mathrm{MZ}$ cotwins $\left(\mathrm{r}_{\mathrm{MZ}}\right)$ and DZ co-twins $\left(\mathrm{r}_{\mathrm{DZ}}\right)$ as:

$$
\mathrm{a}^{2}=2\left(\mathrm{r}_{\mathrm{Mz}}-\mathrm{r}_{\mathrm{DZ}}\right)(\text { eq. } 5)
$$

The shared and nonshared environmental effects may also be calculated as:

$$
\begin{aligned}
\mathrm{e}^{2} \mathrm{~s} & =\mathrm{r}_{\mathrm{MZ}}-\mathrm{a}^{2} \text { (eq. 6) } \\
\mathrm{e}^{2} \mathrm{~ns} & =1-\mathrm{r}_{\mathrm{MZ}} \quad \text { (eq. 7) }
\end{aligned}
$$

Other comparisons among family members may also be used to estimate effects of heredity and environment on a given trait. For example, the similarity of full siblings raised in the same home compared with the similarity of siblings separated at birth and raised in different homes may be used to infer the importance of shared family environment. Alternatively, resemblance between biological parents and their offspring given up for adoption may be used to estimate narrow-sense heritability. The resemblance between MZ twins separated at birth and raised apart also provides a direct estimate of broadsense heritability, while unrelated (adoptive) siblings provide a direct estimate of the influence of a shared family environment. This general variance partitioning approach in behavioral genetic designs is considered more "global," since it broadly classifies genetic and environmental effects and does 
not specifically identify either the genetic or environmental mechanisms involved in a phenotype.

Although equations such as those above may be used to estimate global genetic and environmental effects in traits or behaviors such as antisocial behavior, complex model-fitting routines are more typically used to compute these effects. Model-fitting routines often involve structural equation modeling to represent path models such as that in Figure 2 and employ iterative computational methods to find the best-fitting estimates of parameters $\left(a^{2}, d^{2}\right.$, $\mathrm{e}_{\mathrm{s}}^{2}, \mathrm{e}_{\mathrm{ns}}^{2}$ ) from a set of observed correlations among various types of relatives. Such routines have the advantages of providing: (1) parameter estimates that are constrained to be mathematically reasonable values by, for example, requiring each variance component to be between zero and one; (2) significance tests of each parameter; and, (3) goodness-of-fit indices to evaluate the adequacy of the genetic model.

\section{B. Molecular Genetic Designs}

A variety of other genetic designs attempting to identify specific genes with associations or to identify genes of functional importance in behavior have become increasingly popular in recent years. One design includes studies of QTLs, genes which exert small but significant associations with complex (quantitative) traits. ${ }^{3}$ Whereas the classical designs are useful in identifying broad classes of genetic and environmental influences on complex traits, QTL designs are considered to be a "molecular" approach in that they narrowly specify DNA sequences that increase risk for antisocial behavior.

Two primary approaches taken in QTL designs are (1) a between-family, or population, approach, in which unrelated individuals with varying DNA sequences are compared on some aspect of antisocial behavior; and (2) a within-family approach, in which two or more genetically varying relatives are compared. ${ }^{4}$ Although both approaches can be informative, most researchers agree that within-family designs provide more powerful tests of association between specific genes and traits or behaviors of interest. ${ }^{5}$

Within-family QTL designs are similar to the classical genetic designs, with the important exception that specific alleles or genotypes are measured for each relative, instead of inferred from the overall genetic relationship of two individuals. ${ }^{6}$ For example, a pair of siblings (including DZ twins) could be specified as sharing zero, one, or two alleles at a particular locus. Sibling pairs

3. Quantitative traits are those that exist on a continuum, such as height, weight, extraversion, or general intelligence; qualitative traits are usually all or nothing phenomena such as disease status, eye color, criminal convictions. The term "complex" is often used synonymously with "quantitative."

4. See generally Pak Sham, Recent Developments in Quantitative Trait Loci Analysis, in Behavioral Genetics in the Postgenomic ERA 41 (Robert Plomin et al. eds., 2003).

5. Id.

6. An "allele" is a variation of a particular gene at a given locus. "Genotype" refers to the combination of alleles at a given locus, or more generally to a combination of alleles at two or more loci. 
can be grouped according to their allele-sharing and their phenotypic similarity computed within each group in a manner similar to that of a classical twin study with groups of genetically identical (MZ) and nonidentical (DZ) pairs. A path diagram similar to that in Figure 2, but depicting a sibling design with measured genotypes at a single locus, is provided in Figure 3.

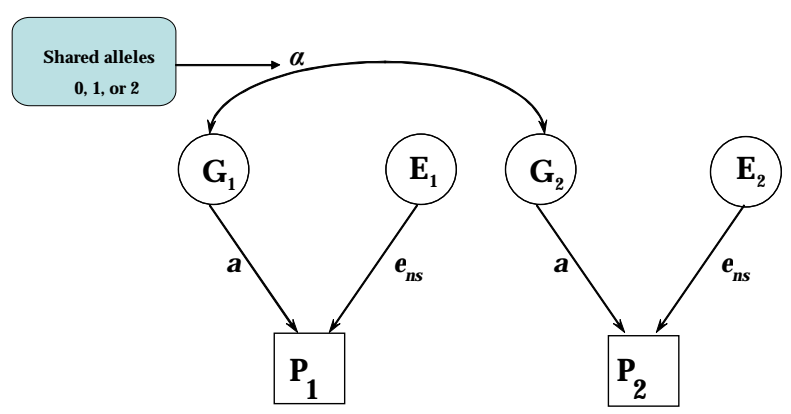

\section{Figure 3: Path Model for Two Siblings (P1 and P2) with Measured Genotype}

Most evidence for a genetic basis of antisocial behavior stems from classical studies estimating the global effects of genes and environment, yet several molecular studies are beginning to emerge identifying specific genetic associations. ${ }^{7}$ Replications of the more recent molecular genetic studies will be critical for wide acceptance of these results.

\section{III}

\section{EVIDENCE FOR A GENETIC BASIS OF ANTISOCIAL BEHAVIOR}

A large number of twin, family, and adoption studies using the classical approach have provided abundant evidence for both genetic and environmental influences on antisocial behavior. These studies vary widely in both their definitions of antisocial behavior and the ways in which it is measured, and results concerning the relative importance of genes and environment vary across both definitions and measures. Before turning to the evidence for genetic and environmental factors in antisocial behavior, it may be helpful to consider how measures and definitions actually vary.

Behavioral genetic studies of antisocial behavior have included studies of juvenile delinquency and adult criminal behavior, of $D S M-I V$ psychiatric disorders related to antisocial behavior, and of trait aggression in both children

7. See infra Part IV.B. 
and adults. ${ }^{8}$ Definitions of antisocial behavior vary widely across these studies, from violations of rules and social norms to various forms of aggression, including self-defense or other reactive forms and proactive behaviors such as bullying. ${ }^{9}$ Definitions of antisocial behavior have also included serious patterns of disruptive and aggressive behavior, such as those observed in conduct disorder or antisocial personality disorder. ${ }^{10}$ Methods of measuring antisocial behavior also vary across studies; some studies are based on official records such as police arrests, court convictions, or school records, ${ }^{11}$ while others rely on behavioral ratings provided by parents or teachers or on self-reporting. ${ }^{12}$ Each assessment method has advantages and disadvantages, with no one definition or method of assessment being clearly superior. ${ }^{13}$ In surveying these studies, it is apparent that males have been more extensively studied, although several investigations of females have also been made. ${ }^{14}$ Antisocial behavior has also been studied across a large portion of the lifespan, from childhood to adolescence to adulthood. ${ }^{15}$

Several reviews of these studies are available, including the most recent meta-analysis by Soo Hyun Rhee and Irwin Waldman. ${ }^{16}$ Rhee and Waldman initially considered nearly twelve dozen published studies of antisocial behavior; their review was narrowed to a group of fifty-one distinct studies that focused primarily on some dimension of antisocial behavior and for which sufficient information on familial correlations was available. ${ }^{17}$ Results were quantitatively aggregated to estimate the relative effect of genetic and environmental influences. When results were combined across studies, the effects were found not to differ across males and females, with significant effects of additive genetic influence $\left(\mathrm{a}^{2}=0.32\right)$, nonadditive genetic influences

8. See Soo Hyun Rhee \& Irwin D. Waldman, Genetic and Environmental Influences on Antisocial Behavior: A Meta-Analysis of Twin and Adoption Studies, 128 PsyCHOL. Bull. 490, 491-92 (2002) (referencing example studies).

9. Id.

10. Id.

11. $I d$.

12. Id.

13. For example, official criminal records represent clear violations of legal norms, but they may be incomplete to the extent that undetected crimes may exist. Self-reported antisocial behavior may be used to assess a broader range of behaviors, including both detected and undetected criminal activity as well as less serious, noncriminal antisocial behavior, but such self-reports will be influenced by the respondent's dishonesty. Parental ratings of antisocial behavior in young children reflect perhaps the most intimate knowledge of the children's behavior (apart from that of the children themselves); however, parents may be unable to judge the child's motivations (such as whether aggressive behavior may be proactive or the result of provocation), and parents have limited observations of the child's behavior outside of the home. Teacher reports provide useful information about school-related behaviors, but these may also lack information about the child's motivations and may not adequately distinguish between victims and perpetrators during conflicts among children.

14. See Rhee \& Waldman, supra note 8, at 515.

15. Id. at 514 .

16. Id.

17. Id. 
$\left(\mathrm{d}^{2}=0.09\right)$, shared $\left(\mathrm{e}_{\mathrm{s}}^{2}=0.19\right)$ and nonshared environment $\left(\mathrm{e}_{\mathrm{ns}}^{2}=0.43\right){ }^{18}$ These effects, are summarized in graphs in Figure 4. The effects of both heredity and environment on antisocial behavior are clearly apparent.

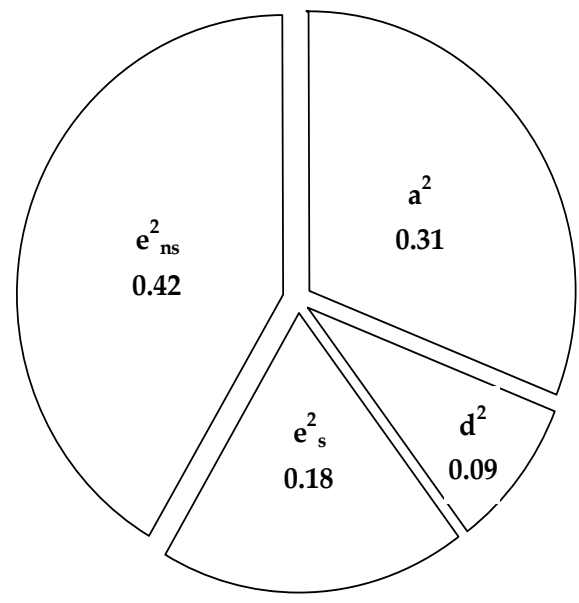

Adapted from Rhee \& Waldman, supra note 10.

Figure 4: Relative Effects of Additive Genetic $\left(\mathrm{a}^{2}\right)$, Nonadditive Genetic $\left(d^{2}\right)$, Shared Environment $\left(e_{s}^{2}\right)$ and Nonshared Environment $\left(e_{n s}^{2}\right)$ Factors in Antisocial Behavior

These genetic and environmental effects differ, however, according to the definition and method of assessing antisocial behavior as well as the age of the subjects when such behavior was studied. ${ }^{19}$ The nonadditive genetic effects appear most strongly for studies of criminal convictions compared to all other definitions of antisocial behavior. ${ }^{20}$ Shared environmental effects were stronger for parental reports of antisocial behavior compared to self-reports and official records, and these shared environmental effects also appeared to diminish from childhood to adulthood. ${ }^{21}$ Nevertheless, it is also noteworthy that age and method of assessment are confounded across studies: studies of younger children tend to rely on parent or teacher reports, while studies of older populations are more apt to use official records or self-report measures of antisocial behavior. ${ }^{22}$ Thus, the larger effect of shared environment during childhood may be due to greater reliance on parental ratings.

22. Id. at 495 . 
One recent study of antisocial behavior in nine- to ten-year-old twins attempted to evaluate the effects of raters' identity on estimates of genetic and environmental influences during childhood. ${ }^{23}$ The study was based on a socioeconomically and ethnically diverse sample of 605 pairs of twins (MZ, DZ same-sex, and DZ opposite-sex) and their caregivers who participated in a comprehensive assessment of the twins' antisocial behavior and related risk factors. $^{24}$ Both the child and his caregiver provided reports of the child's antisocial behavior, in addition to teacher ratings of each child. ${ }^{25}$ Composite measures of antisocial behavior were computed for each rater-parent, teacher, and child-based on several standardized instruments measuring rule-breaking behaviors, including theft and violence, as well as reactive and proactive aggression and conduct disorder symptoms, as rated by each informant. ${ }^{26}$ The pattern of genetic and environmental influences in the composite antisocial behavior measures for these pre-adolescent children, as summarized in Figure 5 , was similar to that found in Rhee and Waldman's meta-analytic review, in that (1) genetic effects were significant for antisocial behavior as assessed by each of the three informants; (2) shared environmental effects were larger for parent and especially for teacher ratings of antisocial behavior as compared to the children's self-report; and (3) the respective magnitudes of genetic and environmental effects were comparable for males and females. ${ }^{27}$ A larger effect of shared environment for childhood antisocial behavior was exhibited, as rated by parents and teachers, although genetic influences are still significant at this early age. The larger shared environmental effect estimated in twin studies relying on parent or teacher ratings of antisocial behavior may thus be due in part to a form of rater bias, rather than to a true, shared environmental effect.

23. Laura A. Baker et al., Genetic and Environmental Bases of Antisocial Behavior in Children (unpublished manuscript, on file with Law and Contemporary Problems).

24. Id.

25. Id.

26. Id.

27. Id. Compare Rhee \& Waldman, supra note 8, at 516-17, 522. 


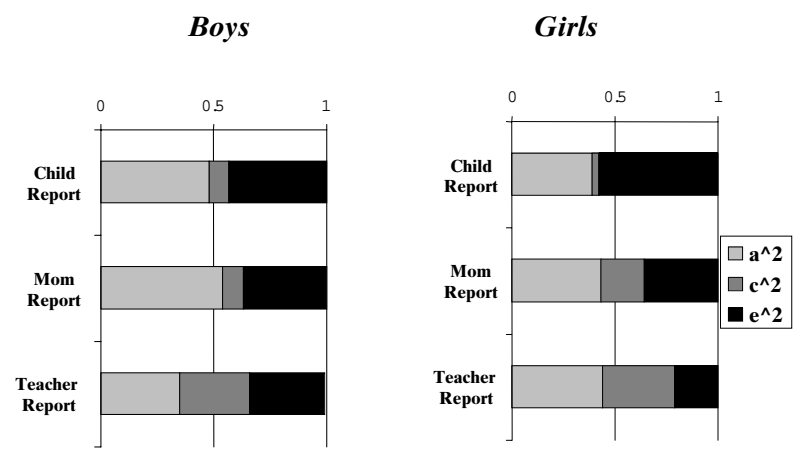

\section{Figure 5: Relative Effects of Additive Genetic ( $\left(^{2}\right)$, Shared Environment $\left(c^{2}\right)$, and Nonshared Environment $\left(e^{2}\right)$ Influences in a Composite Measure of Antisocial Behavior in the USC Twin Study}

Genetic influences in antisocial behavior are present in childhood well before the major risk period for criminality (at age fifteen to twenty-five). These effects do not appear to vary by sex, suggesting that some root biological influences may explain individual differences in antisocial behavior for both males and females. The variability in effect sizes across informants, however, suggests that observing heritability of antisocial behavior may depend on the way in which antisocial behavior is measured. It is therefore important to consider results from a wide range of studies, rather than rely on estimates of heritability from one single study. Meta-analytic reviews are particularly helpful in drawing conclusions across behavior genetic studies. ${ }^{28}$

\section{A. Developmental Changes in Genetic Influences}

Genetic and environmental influences on antisocial behavior also appear to change across a lifespan. Although the Rhee and Waldman review emphasized the decreasing importance of shared family environment $\left(\mathrm{e}_{\mathrm{s}}^{2}\right)$ from childhood to adulthood, ${ }^{29}$ other reviews have suggested heritability may vary in importance at different ages. The direction of difference, however, varies across studies and reviews. Some studies show larger genetic effects during adulthood compared

28. See, e.g., Rhee \& Waldman, supra note 8.

29. Id. 
to childhood and adolescence ${ }^{30}$ while others suggest greater heritability of antisocial behavior during childhood compared to adolescence and adulthood. ${ }^{31}$

To a large extent this discrepancy of results may be due to confounding methods of measurement of antisocial behavior with age of subjects; studies of children tend to rely on parent and teacher reports, while studies of adults utilize official records, such as convictions and self-reported antisocial behavior more often. ${ }^{32}$ Thus, the patterns of genetic and environmental influences across a lifespan are not yet clearly established. In addition, there may be different genetic and environmental influences for various subtypes of individuals with different life-course patterns of offending. It has been suggested that lifecourse, persistent offenders may be at greater genetic risk compared to adolescence-limited offenders, who may in turn be more influenced by social factors like peer influences. ${ }^{33}$ The longitudinal twin or adoption studies required to establish the different genetic influences in developmental subtypes of antisocial individuals have yet to be done.

\section{B. Genetics of Criminal Behavior}

The major reviews of genetic influences in antisocial behavior typically combine a wide range of definitions for what may be considered antisocial. In a legal setting, it may be worth considering studies involving illegal behaviors specifically. Several large-scale twin and adoption studies of criminality have been conducted in various countries, including the United States, ${ }^{34}$ Sweden, ${ }^{35}$ Denmark ${ }^{36}$ and Norway. ${ }^{37}$ Concordance between twins for property crimes such as theft and vandalism has been generally greater for $\mathrm{MZ}$ twin pairs (who are genetically identical) compared to DZ twin pairs (who on average share only fifty percent of their genes).$^{38}$ Property crime convictions among adopted individuals significantly increased when a biological parent was convicted ${ }^{39}$ In

30. See, e.g., Donna R. Miles \& Gregory Carey, Genetic and Environmental Architecture of Human Aggression, 72 J. PERSONALITY \& SOC. PSYCHOL. 207, 207 (1997).

31. See, e.g., Lisabeth Fisher Dilalla \& Irving I. Gottesman, Heterogeneity of Causes for Delinquency and Criminality: Lifespan Perspectives, 1 DeV. \& PsyChopathology 339 (1990).

32. Rhee \& Waldman, supra note 8, at 494.

33. Terrie E. Moffitt, Adolescence-Limited and Life-Course-Persistent Antisocial Behavior: A Developmental Taxonomy, 100 PSYCHOL. REV. 674 (1993).

34. See, e.g., Remi J. Cadoret et al., Genetic-Environmental Interaction in the Genesis of Aggressivity and Conduct Disorders, 52 ARCHIVES OF GEN. PSYCHIATRY 916 (1995).

35. See, e.g., Sören Sigvardsson et al., Predisposition to Petty Criminality in Swedish Adoptees: III. Sex Differences in Validation of the Male Typology, 39 ARCHIVES GEN. PSYCHIATRY 1248 (1982).

36. See, e.g., Barry Hutchins \& Sarnoff A. Mednick, Registered Criminality in the Adoptive and Biological Parents of Registered Male Criminal Adoptees, in GENETIC RESEARCH IN PSYCHIATRY 105 (Ronald R. Fieve et al. eds., 1975).

37. See, e.g., S. Torgersen et al., The Psychometric-Genetic Structure of DSM-III-R Personality Disorder Criteria, 7 J. PERSONALITY DISORDERS 196 (1993).

38. See C. R. Cloninger \& I. I. Gottesman, Genetic and Environmental Factors in Antisocial Behavior Disorders, in THE CAUSES OF CRIME: New BIOlOGICAL APPROACHES 92, 96-100 (S. A. Mednick et al. eds., 1987).

39. Hutchins \& Mednick, supra note 36, at 110; Laura A. Baker et al., Sex Differences in Property Crime in a Danish Adoption Cohort 19 BeHAV. Genetics 355, 360 (1989). 
comparison, conviction rates showed little or no increase in adopted children raised by parents with property crime convictions. ${ }^{40}$ Thus, environmental influences on nonviolent criminality have appeared largely nonfamilial and specific to the individual rather than shared by relatives living together.

Although large sex differences in property crime offenses are evidentmales are arrested far more often than females ${ }^{41}$ - the genetic effects on most criminal behavior are of the same magnitude across the two sexes. ${ }^{42}$ For example, greater MZ than DZ concordance for nonviolent criminal convictions has been found in both male and female same-sex pairs. Opposite-sex DZ twins are often less similar than same-sex DZ pairs, however, suggesting that different genes or environments or both may be important within each sex. ${ }^{43}$ These patterns of genetic influence for nonviolent criminality are consistent with findings for other measures of antisocial behavior, including aggression. ${ }^{44}$ Thus, while there is little or no sex difference in the magnitude of genetic effect on antisocial behavior, some sex-limitation (different genetic effects in males and females) may be evident whereby different genes or environmental factors or both are important within each sex.

Interestingly, the consistent finding of genetic influences on property crimes did not hold true for violent crimes. None of the major adoption studies reported any increased risk for violent conviction as a function of either biological or adoptive parent criminal background, although one twin study did find greater $\mathrm{MZ}$ than $\mathrm{DZ}$ concordance for violent convictions. ${ }^{45}$ The findings of twin, but not of parent-offspring, similarity for violent criminal behavior suggests the possibility of nonadditive genetic effects, which would result in increased resemblance for siblings, but not for parents and offspring.

Studies of younger subjects have typically not distinguished between violent and nonviolent offending. Nor have self-report methods of assessment been frequently used in studies of delinquent behavior in children. One exception is the University of Southern California (USC) twin study of antisocial behavior. ${ }^{46}$ These nine- to ten-year-old twins completed a self-report Delinquency Interview ${ }^{47}$ which provided separate scales for recording nonviolent delinquent behavior. These scales included minor rule breaking, such as watching TV

40. Hutchins \& Mednick, supra note 36 .

41. JAMES Q. Wilson \& Richard J. HERRNSTEIN, CRIME AND HumAn NATURE 104-12 (1985); cf. Janet S. Hyde, How Large Are Gender Differences in Aggression? A Developmental Analysis, 20 DEVELOPMENTAL PSYCHOL. 722 (1984) (discussing gender variation in aggression).

42. See Rhee \& Waldman, supra note 8, at 494 (noting that genetic effects on antisocial behavior are equal between the sexes, but that genetic effects on aggression are not equal).

43. See Cloninger \& Gottesman, supra note 38.

44. Rhee \& Waldman, supra note 8.

45. Cloninger \& Gottesman, supra note 38.

46. Baker et al., supra note 23 .

47. Laura A. Baker \& Adrian Raine, The Delinquency Interview for Children (DI-C): A Selfreport Measure of Antisocial Behavior (2005) (unpublished manuscript, on file with Law and Contemporary Problems). 
without permission, theft, damaging property, and truancy. ${ }^{48}$ The interview also contained three scales of violent behaviors, which involve hitting, shoving, or biting (1) one's twin, (2) another sibling, or (3) a child outside of one's family. ${ }^{49}$ In contrast to the large genetic influence on criminality in adults, these childhood behaviors appeared to be explained primarily by environmental (both $\mathrm{e}_{\mathrm{s}}^{2}$ and $\mathrm{e}_{\mathrm{NS}}^{2}$ ) factors. ${ }^{50}$ There were, however, small genetic influences in minor rule breaking $\left(\mathrm{a}^{2}=0.20\right)$ and theft $\left(\mathrm{a}^{2}=0.12\right),{ }^{51}$ suggesting that these effects may begin to emerge as a propensity to engage in nonviolent delinquent behavior prior to adolescence. Consistent with research on adult offending, as well as the Rhee and Waldman meta-analysis of antisocial behavior, ${ }^{52}$ the magnitude of genetic and environmental influences in the USC twin study were not significantly different in boys and girls. ${ }^{53}$ It may be expected that genetic influences on nonviolent behaviors will increase in these children as they move into the high-risk period of adolescence.

Developmental factors may indeed play an important role in genetic influences for early rule-breaking and eventual for law-breaking behaviors. Other moderating factors besides age must also be considered in understanding how genetic factors may operate in antisocial behavior. In particular, genetic influences in criminality appear to be moderated by environmental factors, as discussed below. ${ }^{54}$

\section{Genetic Studies of Psychiatric Outcomes Related to Antisocial Behavior}

Antisocial behavior and aggression play key roles in the diagnoses of three mental disorders. As discussed in this section, antisocial personality disorder in adults may involve aggressive, impulsive, reckless, and irresponsible behavior. It may also be very difficult for individuals with antisocial personality disorder to maintain jobs and personal relationships or to otherwise conform to social or cultural norms. In children, conduct disorder is thought to be indicated by the externalization of problems in the form of aggression towards people and animals, destruction of property, dishonesty, theft, and other serious violations of age-appropriate rules such as truancy. In addition, a persistent pattern of negative, hostile, overly aggressive, and defiant behavior in children is characteristic of oppositional defiant disorder (ODD). These disorders are typically diagnosed through interviews and questionnaires.

The effects of genes and environment on these psychiatric disorders have been investigated in both twin and adoption studies. Significant genetic

48. $I d$.

49. $I d$.

50. Adrian Raine et al., Biological Risk Factors for Antisocial and Criminal Behavior, in CRIME AND SCHIZOPHRENIA: CAUSES AND CURES (Adrian Raine ed.) (forthcoming).

51. Baker \& Raine, supra note 47.

52. Rhee \& Waldman, supra note 8 .

53. Baker \& Raine, supra note 47.

54. See infra Part V.A. 
influences have been consistently reported for antisocial-personality-disorder symptoms in twin samples, while shared environmental influences have been reported to be less important. ${ }^{55}$ Furthermore, adoption studies have also found significant genetic effects for antisocial-personality-disorder symptom counts. ${ }^{56}$ In addition, significant genetic influences on conduct disorder have been reported in twin $^{57}$ and adoption studies. ${ }^{58}$ In contrast to adult antisocial personality disorder, for conduct disorder, shared family environmental influences have been found to be of greater importance during childhood. ${ }^{59}$

\section{Antisocial Personality Disorder}

Antisocial personality disorder is one of the most extensively studied personality disorders. Individuals with this disorder are impulsive, aggressive, aloof, and are thought to have diminished capabilities for work, love, guilt, and cooperation with others. ${ }^{60}$ Antisocial personality disorder begins in childhood with substantial behavior problems either at school or at home. ${ }^{61}$ The disorder is typified by antisocial behavior in a broad range of social and personal contexts. Impulsive-aggressive behavior is most prominent during childhood. ${ }^{62}$ These behaviors include fighting, setting fires, running away from home, cruelty to animals, and conflicts with authority figures. ${ }^{63}$ In adulthood, the impulsiveaggressive behaviors persist and are associated with impairments in work and social situations. ${ }^{64}$ Individuals with antisocial personality disorder tend to

55. William M. Grove et al., Heritability of Substance Abuse and Antisocial Behavior: A Study of Monozygotic Twins Reared Apart, 27 BiologiCAL PSYCHIATRY 1293 (1990); G. Carey, Multivariate Genetic Relationship Among Drug Abuse, Alcohol Abuse and Antisocial Personality, 3 PSYCHIATRIC GeNETICS 141 (Paper Presented at the Third World Congress on Psychiatric Genetics, 1993); Michael J. Lyons et al., Differential Heritability of Adult and Juvenile Antisocial Traits, 3 PSYCHIATRIC Genetics 117 (Paper Presented at the Third World Congress on Psychiatric Genetics, 1993); Michael J. Lyons, A Twin Study of Self-Reported Criminal Behaviour, in GENETICS OF CRIMINAL AND ANTISOCIAL BEHAVIOR 61 (Gregory R. Bock \& Jamie A. Goode eds., 1996).

56. Cadoret et al., supra note 34; Remi J. Cadoret et al., An Adoption Study of Genetic and Environmental Factors in Drug Abuse, 43 ARCHIVES GEN. PSYCHIATRY 1131 (1986).

57. Lindon J. Eaves et al., Genetics and Developmental Psychopathology: 2. The Main Effects of Genes and Environment on Behavioral Problems in the Virginia Twin Study of Adolescent Behavioral Development, 38 J. CHILD PSYCHOL. \& PSYCHIATRY 965 (1997).

58. Remi J. Cadoret et al., Evidence for Gene-Environment Interaction in the Development of Adolescent Antisocial Behavior, 13 BEHAV. GENETICS 301 (1983); Cadoret et al., supra note 34.

59. Laura Baker, The Nature-Nurture Problem in Violence, in INTERNATIONAL HANDBOOK OF VIOLENCE RESEARCH 589 (Wilhelm Heitmeyer \& John Hagan eds., 2003); Michael J. Lyons et al., Differential Heritability of Adult and Juvenile Antisocial Traits, 52 ARCHIVE GEN. PSYCHIATRY 906 (1995).

60. C. Robert Cloninger et al., Epidemiology and Axis I Comorbidity of Antisocial Personality, in HANDBOOK OF ANTISOCIAL BEHAVIOR 12 (David M. Stoff et al. eds., 1997).

61. LeE N. Robins, DeViant Children Grown UP: A SOCIOLOGiCAl And Psychiatric STUDY OF SOCIOPATHIC PERSONALITY (1966).

62. See Lee N. Robins et al., Antisocial Personality, in PSYCHIATRIC DisORDERS IN AMERICA: The EPIDEMilogic CATChMENT AREA STUdy 258, 264 (Lee N. Robins \& Darrel A Regier eds., 1991) (describing the common remission of the disorder as the individual advances into adulthood).

63. Id. at 259-60.

64. Id. at 260 . 
change jobs repeatedly, both by getting fired and by quitting. ${ }^{65}$ They also frequently use and abuse alcohol and drugs. ${ }^{6}$

Antisocial personality disorder is more prevalent in males than females, regardless of age or ethnicity. ${ }^{67}$ Furthermore, rates of this disorder are higher in people who are related to someone with it when compared to the normal population. ${ }^{68}$ In addition, even though the rates of antisocial personality disorder are lower in females, affected female probands normally have more affected relatives than male probands. ${ }^{69}$ Thus, females may require stronger cultural and biological influences than males to become antisocial. ${ }^{70}$

\section{Conduct Disorder}

Conduct disorder is a childhood onset disorder that is emerging as one of the most common child psychiatric disorders. ${ }^{71}$ The disorder manifests as a repetitive and persistent pattern of adolescent antisocial behavior in which the basic rights of others or societal norms and rules are violated. ${ }^{72}$ In general, conduct disorder is considered to be a relatively severe and clinical form of antisocial behavior. ${ }^{73}$ It is associated with a plethora of negative outcomes such as depression and anxiety, drug use and abuse, and, in adults, antisocial personality disorder. ${ }^{74}$

Conduct disorder in childhood and adolescence is a strong predictor of antisocial behavior in adulthood. Studies using official court records have shown that $50 \%$ to $70 \%$ of children (youths) who met criteria for conduct disorder, or were arrested for delinquent acts during childhood or adolescence, are arrested in adulthood. ${ }^{75}$ Similarly, children with high instances of antisocial behaviors have been found to have a $43 \%$ chance of meeting criteria for

65. Id.

66. Marian B.M. van den Bree et al., Antisocial Personality and Drug Use Disorders-Are They Genetically Related?, in THE SCIENCE, TREATMENT, AND PREVENTION OF ANTISOCIAL BEHAVIORS: ApPliCAtion to THE CRIMINAL JusticE System 8-1, 8-1 to 8-2 (Diane H. Fishbein ed., 2000).

67. Robins et al, supra note 62, at 271.

68. Cloninger \& Gottesman, supra note 38.

69. Van den Bree et al., supra note 66, at 8-6.

70. Id.

71. Jane Scourfield et al., Conduct Problems in Children and Adolescents: A Twin Study, 61 ARCHIVES GEN. PSYCHIATRY 489 (2004). See also Jessie C. Anderson et al., DSM-III Disorders in Preadolescent Children, 44 ARCHIVES OF GEN. PSYCHIATRY 69 (1987); Patricia Cohen et al., An Epidemiological Study of Disorders in Late Childhood and Adolescence-I. Age-and Gender-Specific Prevalence, 34 J. CHILD PSYCHOL. \& PSYCHIATRY 851 (1993) (detailing studies of common childhood disorders which include conduct disorder).

72. American Psychological Ass'n, Diagnostic and Statistical Manual of Mental DISORDERS 85 (4th ed. 1994).

73. Heather L. Gelhorn et al., Genetic and Environmental Influences on Conduct Disorder: Symptom, Domain, and Full-Scale Analyses, 46 J. CHILD PSYCHOL. \& PSYCHIATRY 580, 580 (2005).

74. Id.

75. Rolf Loeber, Antisocial Behavior: More Enduring than Changeable?, 30 J. AM. ACAD. CHILD \& AdOLESCENT PSYCHIATRY 393, 393 (1991). See also Rolf Loeber, Development and Risk Factors of Juvenile Antisocial Behavior and Delinquency, 10 CLINICAL PSYCHOL. REV. 1 (1990); Rolf Loeber, The Stability of Antisocial and Delinquent Child Behavior: A Review, 53 CHILD DEV. 1431 (1982) (detailing studies involving the development and stability of juvenile delinquency into adulthood). 
antisocial personality disorder during adulthood, ${ }^{76}$ and $40 \%$ of institutionally reared boys and $35 \%$ of institutionally reared girls who met a relaxed DSM-III criteria for conduct disorder in childhood later met criteria for antisocial personality disorder in adulthood. ${ }^{77}$ Furthermore, a study following a sample of boys and girls who had attended a large psychiatric clinic in London into their adulthood found that $43 \%$ of the youths who had conduct disorder during childhood also met criteria for antisocial personality disorder during adulthood, compared to only $13 \%$ of youths who had not had conduct disorder in childhood. $^{78}$

Not all youth with conduct disorder engage in antisocial acts in adulthood, raising the question of what factors might set these youths apart and predict whether a child with conduct disorder will become antisocial as an adult. Children who met criteria for conduct disorder and who had a biological parent with antisocial personality disorder are more likely to meet criteria for antisocial personality disorder themselves. ${ }^{79}$ A history of antisocial personality disorder in a parent is the strongest predictor of persistence of conduct disorder from childhood into adolescence. ${ }^{80}$

Researchers have begun to recognize that genetic factors contribute critically to the development of conduct problems in children. ${ }^{81}$ Recent studies have indicated that conduct disorder is significantly heritable, with estimates ranging from $27 \%$ to $78 \% .^{82}$ Some twin studies have demonstrated the significance of shared family environmental influences in conduct disorder, while several other studies have found no such significant shared factors. ${ }^{84}$ Predominantly, significant genetic factors do appear to be influencing antisocial-behavior-related psychiatric disorders such as conduct disorder and antisocial personality disorder.

76. RoBINS, supra note 61 , at $141-42$.

77. Mark Zoccolillo et al., The Outcome of Childhood Conduct Disorder: Implications for Defining Adult Personality Disorder and Conduct Disorder, 22 PsYCHOL. MED. 971, 976 (1992). See generally Benjamin B. Lahey \& Rolf Loeber, Attention-Deficit/Hyperactivity Disorder, Oppositional Defiant Disorder, Conduct Disorder, and Adult Antisocial Behavior: A Life Span Perspective, in HANDBOOK OF ANTISOCIAL BEHAVIOR, supra note 60, at 51 (describing the developmental relationship between behavior disorders in childhood and the appearance of antisocial disorders in adulthood).

78. Lahey \& Loeber, supra note 77, at 57 (citing Richard Harrington et al., Adult Outcomes of Childhood and Adolescent Depression: II. Links with Antisocial Disorders, 30 J. AM. CHILD \& ADOLESCENT PSYCHIATRY 434 (1991)).

79. See RoBINS, supra note 61, at 163-66.

80. See, e.g., Lahey \& Loeber, supra note 77.

81. Scourfield et al., supra note 71, at 489.

82. See Gelhorn et al., supra note 73; Scourfield et al., supra note 71; Anita Thapar et al., Examining the Comorbidity of ADHD-Related Behaviours and Conduct Problems Using a Twin Study Design, 179 BRIT. J. PSYCHIATRY 224 (2001); Frederick L. Coolidge et al., Heritability and the Comorbidity of Attention Deficit Hyperactivity Disorder with Behavioral Disorders and Executive Function Deficits: A Preliminary Investigation, 17 DEVELOPMENTAL NEUROPSYCHOLOGY 273 (2000); Eaves et al., supra note 57.

83. Gelhorn et al., supra note 73, at 588; Thapar et al., supra note 82, at 226. Cadoret et al., supra note 34 .

84. Scourfield et al., supra note 71, at 494; Eaves et al., supra note 57, at 973. 


\section{Oppositional Defiant Disorder}

Similar to conduct disorder, oppositional defiant disorder is a behavioral disturbance characterized by aggressive and antisocial acts. ${ }^{85}$ Oppositional defiant disorder encompasses primarily verbal aggression, such as losing one's temper, and inharmonious interpersonal behavior, such as blaming others and seeking revenge, whereas conduct disorder "includes physically aggressive behaviors ranging in severity from bullying to forced sexual activity and antisocial acts, including theft, destruction of property, and violation of agenormative rules, such as truancy." ${ }^{16}$ When combined, oppositional defiant disorder, and conduct disorder are among the most common psychiatric disorders in childhood and adolescence. Recent studies estimate the prevalence rates for oppositional defiant disorder at $1.8 \%$ to $3.9 \%$, and conduct disorder at $3.3 \%$ to $6.6 \%{ }^{87}$

As with antisocial personality disorder and conduct disorder, twin studies have also been utilized to investigate the heritability of oppositional defiant disorder. Several twin studies have found significant genetic influences in oppositional defiant disorder symptoms with heritability estimates ranging from $14 \%$ to $65 \% .^{88}$

\section{Genetic Influences on Correlates of Antisocial Behavior}

Although studies reviewed so far provide direct evidence for genetic influences on antisocial behavior, numerous other investigations also provide indirect evidence by examining the genetic underpinnings of traits and behavior that predict or correlate with antisocial behavior. These traits include personality traits, such as impulsivity, and cognitive factors, such as attention and other executive-function deficits. These correlates of antisocial behavior are manifested in another psychiatric disorder, attention deficit hyperactivity disorder (ADHD), which also shows comorbidity with conduct disorder and aggressive behavior in children. Reviewing evidence for genetic influences in these correlated traits can help shed light on the nature of the genetic mechanisms that may underlie antisocial behavior.

85. Emily Simonoff, Gene-Environment Interplay in Oppositional Defiant and Conduct Disorder, 10 CHILd \& Adolescent PsychiAtric Clinics N. AM. 351, 351 (2001).

86. $I d$.

87. Id., at 352 .

88. Coolidge et al., supra note 82, at 282 tbl.4 (finding a heritability estimate of 0.61); Eaves et al., supra note 57, at 974 tbl.3 (finding heritability of fourteen percent for girls as measured by their fathers' responses to questionnaires and heritability of sixty-five percent for boys as measured from interviews with their fathers). 


\section{Impulsivity}

Individuals are differentially susceptible to antisocial behavior, due perhaps in part to variations in personality characteristics such as impulsivity. ${ }^{89}$ These personality correlates of antisocial behavior are also heritable. Data from large twin and adoption studies have suggested that traits related to repetitive, aggressive behavior, such as impulsivity, drug abuse, and neurological deficits, are significantly heritable. In a review of eleven behavioral genetic studies on impulsive behavior and aggressive behavior, at least five demonstrated significant heritability for these traits..$^{90}$ In addition, three out of three studies conducted on adolescents demonstrated negative results, but three out of four studies on adults found significant heritabilities for impulsivity and aggression. ${ }^{91}$ In the latter studies, the heritabilities found were $0.72,{ }^{92} 0.44,{ }^{93}$ and $0.41,{ }^{94}$ indicating that impulsivity and aggression are significantly heritable. ${ }^{95}$ Furthermore, the heritability of self-reported personality traits related to impulsiveness and irritability in twins reared together and apart showed heritability rates that ranged from $20 \%$ to $62 \%{ }^{96}$ Not only these, but other twin studies have also indicated a strong genetic heritability for impulsivity. ${ }^{97}$ Genes may therefore modulate behaviors that involve impulse control, which can lead to manifestations such as conduct disorder, antisocial personality disorder, ADHD and alcoholism. ${ }^{98}$

\section{Attention Deficit Hyperactivity Disorder}

ADHD is a highly disabling condition that normally begins during early childhood. ${ }^{99}$ It is characterized by pervasive inattention, overactivity, and impulsiveness. Children with ADHD not only experience educational failures in school, but they also experience problems with relationships and poor selfesteem. $^{100}$ In addition, they are at risk for developing behavioral, psychiatric, and social difficulties in adulthood, including antisocial behavior.

89. David Goldman \& Diana H. Fishbein, Genetic Bases for Impulsive and Antisocial BehaviorsCan Their Course Be Altered?, in THE SCIENCE, TREATMENT, AND PREVENTION Of ANTISOCIAL BEHAVIORS: APPLICATION TO THE CRIMINAL JUSTICE SYSTEM, supra note 70, at 9-1, 9-2.

90. Emil F. Coccaro et al., Heritability of Irritable Impulsiveness: A Study of Twins Reared Together and Apart, 48 PSYCHIATRY RES. 229, 237 (1993).

91. Goldman \& Fishbein, supra note 89, at 9-6.

92. J. Phillipe Rushton et al., Altruism and Aggression: The Heritability of Individual Differences, 50 J. PERSONALITY \& SOC. PSYCHOL. 1192, 1194 (1986).

93. Auke Tellegen et al., Personality Similarity in Twins Reared Apart and Together, 54 J. PERSONALITY \& SOC. PSYCHOL. 1031, 1036 (1988).

94. Coccarro et al., supra note 90 at 234-35.

95. Goldman \& Fishbein, supra note 89, at 9-6.

96. Coccarro et al., supra note 90 at 234-35.

97. See, e.g., Yoon-Mi Hur \& Thomas J. Bouchard, Jr., The Genetic Correlation Between Impulsivity and Sensation Seeking Traits, 27 BEHAV. GENETICS 455 (1997).

98. Goldman \& Fishbein, supra note 89, at 9-2.

99. Russell A. Barkley, Genetics of Childhood Disorders: XVII. ADHD, Part 1: The Executive Functions and ADHD, 39 J. AM. CHILD \& ADOLESCENT PSYCHIATRY 1064, 1064 (2000); Anita Thapar et al., Genetic Basis of Attention Deficit and Hyperactivity, 174 BRIT. J. PSYCHIATRY 105, 105 (1999).

100. Thapar et al., supra note 99 at 105. 
Childhood ADHD has been linked to antisocial behavior in two ways. First, research has shown that children with ADHD are more likely than children without ADHD to exhibit antisocial behavior during adolescence and adulthood. ${ }^{101}$ Second, it appears that the persistence of conduct disorder over time is worse for youths who also display symptoms of ADHD. ${ }^{102}$ Several studies have suggested that youths who exhibit both antisocial behavior and ADHD manifest more severe forms of antisocial behavior, particularly greater physical aggression. ${ }^{103}$ Although some youths classified as ADHD exhibit high levels of either inattention or hyperactivity-impulsivity, most exhibit high levels of both types of symptoms. Developmentally, ADHD symptoms tend to persist. Studies have reported strong continuity in overactivity and attention problems from ages six to seven to ages sixteen to eighteen. ${ }^{104}$

Many classical genetic studies have examined genetic influences on ADHD ${ }^{105}$ as have adoption studies, which provide strong evidence suggesting a genetic basis for both inattention and hyperactivity. ${ }^{106}$

Early research showed higher prevalence rates of hyperactivity among biological parents and second-degree relatives of children with hyperactivity, compared with controls. Furthermore, family studies have found that full siblings of affected children show higher rates of hyperactivity than half-siblings... In a [more] recent series of family studies, where standardised interviews ... were used, relatives of affected male and female probands were found to be at increased risk for the disorder.... Early adoption studies found significantly higher rates of hyperactivity among biological parents of children with hyperactivity $(7.5 \%)$ compared with adoptive parents (2.1\%)... Adoption research has also found that biological parents of hyperactive children demonstrate significantly poorer performance on cognitive measures of attention, compared with adoptive parents. ${ }^{107}$

Another adoption study using both biologically related and unrelated international adoptees identified a strong genetic component $\left(h^{2}=0.47\right)$ for attention problems, which are highly related to the diagnoses of ADHD, ${ }^{108}$

Correlations for symptoms of hyperactivity and inattention are greater for MZ twins than for DZ twins ${ }^{109}$ with heritability estimates ranging from $39 \%$ to

101. Hechtman, L., Weiss, G., \& Perlman, T. Hyperactives as Young Adults: Past and Current Substance Abuse and Antisocial Behavior, 54 AM. J. ORTHOPSYCHIATRY 415, 415-25 (1984); or Satterfield, R., Rutter, M., \& Schell, A. M., A Prospective Study of Delinquency in 110 Adolescent Boys with Attention Deficit Disorder and 88 Normal Adolescent Boys, 139 AM. J. PSYCHIATRY, 795, 795-98 (1982).

102. See Benjamin Lahey \& Rolf Loeber, Attention-Deficit/Hyperactivity Disorder, Oppositional Defiant Disorder, Conduct Disorder, and Adult Antisocial Behavior: A Life Span Perspective, in HANDBOOK OF ANTISOCIAL BEHAVIOR, supra note 60, at 51.

103. See Lahey \& Loeber, supra note 102; Offord et al., Delinquency and hyperactivity, J. NERVOUS \& MENTAL DiSEASE, 167, 734-41 (1979).

104. Jonna Kuntsi et al., Genetic Influences on the Stability of Attention-Deficit/Hyperactivity Disorder Symptoms from Early to Middle Childhood, 57 BIOLOGICAL PSYCHIATRY 647, 647 (2005).

105. Thapar et al., supra note 99, at 109; BARKLEY, supra note 99.

106. RuSSEll A. BARKLEY, ADHD AND THE NATURE OF SELF-CONTROL 37-41 (1997).

107. Thapar et al., supra note 99, at 106-09. Indeed, first-degree relatives of male probands were five times more likely to be diagnosed with ADHD than relatives of the normal controls.

108. Edwin J.C.G. van den Oord et al., A Study of Problem Behaviors in 10- to 15-Year-Old Biologically Related and Unrelated International Adoptees, 24 BEHAV. GENETICS 193, 201 (1994). 
91\%. ${ }^{110}$ Several large-scale twin studies have also separately examined the trait of hyperactivity-impulsivity and attribute a large portion of variance to genetic factors (with an average heritability of approximately 80\%). ${ }^{111}$ Furthermore, such a genetic contribution may increase as the scores along this trait become more extreme, although this is under debate. ${ }^{112}$

How important are environmental factors in ADHD symptoms? Shared environmental factors contribute little, if anything, to the underlying symptoms of ADHD, typically accounting for only about $5 \%$ or less of the variance among individuals. ${ }^{113}$ There has been some suggestion, however, that shared environmental influences might contribute to the persistence of behavior problems across development. ${ }^{114}$

Twin studies also indicate the importance of nonshared environmental factors, which may include unique individual experiences as well as biological factors that might not be genetic in origin. ${ }^{115}$ Such nonshared environmental factors might be events that affected one twin but not the other, such as neurological injuries, or differences in manner or character that received

109. Robert Goodman \& Jim Stevenson, A Twin Study of Hyperactivity-II. The Aetiological Role of Genes, Family Relationships and Perinatal Adversity, 30 J. CHILD PSYCHOL. \& PSYCHIATRY 691 (1989); Jim Stevenson, Evidence for a Genetic Etiology in Hyperactivity in Children, 22 BEHAV. Genetics 337, 342 (1992); Jacquelyn J. Gillis et al., Attention Deficit Disorder in Reading-Disabled Twins: Evidence for a Genetic Etiology, 20 J. ABNORMAL CHILD PSYCHOL. 303, 304 (1992); Craig Edelbrock et al., A Twin Study of Competence and Problem Behavior in Childhood and Early Adolescence, 36 J. CHILD PSYCHOL. \& PSYCHIATRY 775, 779 (1995); Anita Thapar et al., Childhood Hyperactivity Scores Are Highly Heritable and Show Sibling Competition Effects: Twin Study Evidence, 25 Behav. Genetics 537, 539 (1995); Eaves et al., supra note 57; Florence Levy et al., AttentionDeficit Hyperactivity Disorder: A Category or a Continuum? Genetic Analysis of a Large-Scale Twin Study, 36 J. AM. ACAD. CHILD \& ADOLESCENT PSYCHIATRY 737, 738 (1997); Dianne K. Sherman et al., Attention-Deficit Hyperactivity Disorder Dimensions: A Twin Study of Inattention and ImpulsivityHyperactivity, 36 J. AM. ACAD. CHILD \& ADOLESCENT PSYCHIATRY 745, 746 (1997).

110. Thapar et al., supra note 99, at 107.

111. Stephen V. Faraone, Discussion of "Genetic Influence on Parent-Reported Attention-Related Problems in a Norwegian General Population Twin Sample,” 35 J. AM. ACAD. CHILD \& ADOLESCENT PSYCHIATRY 596 (1996); Helene Gjone et al., Changes in Heritability Across Increasing Levels of Behavior Problems in Young Twins, 26 BEHAV. GENETICs 419 (1996); Levy et al., supra note 109; Rhee \& Waldman, supra note 8; Sherman et al., supra note 109; Judy Silberg et al., Genetic and Environmental Influences on the Covariation Between Hyperactivity and Conduct Disturbance in Juvenile Twins, 37 J. CHILD PsyCHOL. \& PsYCHIATRY 803 (1996); Edwin J.C.G. van den Oord et al., A Genetic Study of Maternal and Paternal Ratings of Problem Behaviors in 3-Year-Old Twins, 105 J. ABNORMAL PSYCHOL. 349 (1996).

112. Neilson Martin et al., Observer Effects and Heritability of Childhood Attention-Deficit Hyperactivity Disorder Symptoms, 180 BRIT. J. PSYCHIATRY 260 (2002); Thapar et al., supra note 82; Farone, supra note 111; Gjone et al., supra note 111; Levy et al., supra note 109; Soo Hyun Rhee et al., Sex Differences in Genetic and Environmental Influences on DSM-III-R Attention Deficit Hyperactive Disorder (ADHD), 108 J. ABNORMAL PSYCHOL. 24, 37-38 (1999); Sherman et al., supra note 109; Thapar et al., supra note 109; Edwin J.C.G. van den Oord et al., supra note 111.

113. See, e.g., Levy et al., supra note 109; Sherman et al., supra note 109; Silberg et al., supra note 111.

114. Edwing J.G.C. van den Oord \& David C. Rowe, Continuity and Change in Children's Social Maladjustment: A Developmental Behavior Genetic Study, 33 DEVELOPMENTAL PsYCHOL. 319 , 329 (1997).

115. BARKLEY, supra note 99 , at $40-41$. 
different treatment from the parents of the children. Nearly $15 \%$ to $20 \%$ of the variance in ADHD symptoms is due to nonshared environmental factors. ${ }^{116}$

In summary, twin, family, and adoption studies have consistently shown a strong genetic contribution to ADHD. Influential environmental factors appear to be largely of the nonshared variety, although shared family environment could possibly influence the persistence of symptoms over time.

\section{Executive Function}

Executive function has been defined in the literature as a unique domain of cognitive abilities that involves organization in space and time, selective inhibition, response preparation, goal attainment, planning, and cognitive flexibility. ${ }^{117}$ This set of functions is thought to be relatively independent from other cognitive functions, such as sensations, perception, language, and memory, yet it is also thought to overlap with attention, reasoning, and problem solving. ${ }^{118}$ The neural mechanisms underlying executive function have not been clearly defined, but it is thought that they are mediated by the prefrontal cortices of the brain. ${ }^{119}$ Significant differences in one or more measures of executive function have been found between children who had ADHD and control children. ${ }^{120}$ Furthermore, deficits in executive function can arise as a consequence of many different factors, including genetic as well as traumatic brain injuries. ${ }^{121}$

The most typical head injuries include damage to the frontal lobes, which are responsible for planning and the inhibition of impulsive behavior. ${ }^{122}$ Therefore, damage to the frontal lobes will often result in increased impulsive and aggressive behavior in response to external provocation. ${ }^{123}$ There is also a link between executive dysfunctions and antisocial behavior, whereby antisocial offenders have been found to demonstrate greater neuropsychological deficits. ${ }^{124}$

In contrast to the numerous studies showing high heritability of disorders such as ADHD and conduct disorder, genetic studies of executive function deficits are much scarcer. One reason might be that, unlike ADHD, conduct disorder, or even oppositional defiant disorder, the Diagnostic and Statistical

116. Silberg et al., supra note 111, at 809; Alison Pike \& Robert Plomin, Importance of Non-shared Environmental Factors for Childhood and Adolescent Psychopathology, 35 J. AM. ACAD. CHILD \& ADOLESCENT PSYCHIATRY 560 (1996).

117. See, e.g., Frederick L. Coolidge et al., Are Personality Disorders Psychological Manifestations of Executive Function Deficits? Bivariate Heritability Evidence from a Twin Study, 34 BEHAV. GENETICS 75, 75-78 (2004).

118. Coolidge et al., supra note 82 .

119. Bruce F. Pennington \& Sally Ozonoff, Executive Functions and Developmental Psychopathology, 37 J. CHILD PSYCHOL. \& PSYCHIATRY 51, 51 (1996).

120. See id. at 58-65.

121. Adrian Raine et al., Neurocognitive Impairments in Boys on the Life-Course Persistent Social Path, 114 J. ABNORMAL PSYCHOL. 38 (2005).

122. Coolidge et al., supra note 117.

123. Id.

124. See AdRiAn RAINe, THE PSychopathology OF CRIME: CRIMINAL BeHAVIOR AS CLINICAL DISORDER 215-16 (1993). 
Manual of Mental Disorders includes no established criteria for executive function deficits, so "a standard syndromal description and consensus of criteria are lacking." ${ }^{\prime 25}$ However, heritability studies of ADHD and evidence that ADHD is comorbid with executive function deficits indirectly suggest a substantial and even primary genetic link. ${ }^{126}$ Two recent studies that explored the etiology of executive function deficits in children demonstrated that executive function deficits are in fact highly heritable $\left(\mathrm{h}^{2}=0.77\right) .{ }^{127}$

\section{Substance Use and Abuse}

The relationship between alcohol use and violence has been well documented ${ }^{128}$ but is not fully understood. Illicit drug use has been connected to violence and antisocial behavior, but whether drug or alcohol use has a direct effect on violence has been debated. ${ }^{129}$ In general, the nature of the association between substance use and violence may stem from several possible sources: it might be due to shared common causes, such as genetic or temperamental traits, antisocial personality disorder, or parental modeling of heavy substance use and violence. ${ }^{130}$

Recent literature has focused on family and twin studies to shed more light on the relationship between antisocial behavior and substance use. ${ }^{131}$ Like antisocial behavior, substance dependence also tends to run in families, with most family resemblance being explained by genetic factors and not by shared family environment. ${ }^{132}$ In addition, the relative influence of genetic and environmental factors on substance dependence tends to be the same in both men and women, although women may require greater familial loading, that is, greater genetic propensity or liability, to express these disorders. ${ }^{133}$ Establishing that both antisocial behavior and substance dependence are heritable, however, does not necessarily mean that the same genetic or environmental factors influence both disorders. Studies investigating both disorders simultaneously are required to understand their genetic and environmental overlap.

Several twin studies show significant genetic overlap among disinhibitory syndromes, such as conduct disorder and alcohol dependence, child and

125. Coolidge et al., supra note 82, at 275; See generally AMERICAN PSYCHOLOGICAL Ass'N, supra note 72 .

126. Coolidge et al., supra note 82 , at 275.

127. Id.

128. Alcohol use is presumed to contribute to violence because of the pharmacological properties of the drug, as well as expectancies and societal norms surrounding these aspects. See generally Helene Raskin White, Alcohol, Illicit Drugs, and Violence, in HANDBOOK OF ANTISOCIAL BEHAVIOR, supra note 60 , at 511 .

129. White, supra note 128.

130. Id. at 512 .

131. Brian M. Hicks et al., Family Transmission and Heritability of Externalizing Disorders: A Twin-

Family Study, 61 ARCHIVES OF GEN. PSYCHIATRY 922, 922-23 (2004).

132. Id.

133. Kathleen R. Merikangas et al., Familial Transmission of Substance Use Disorders, 55 ARCHIVES GEN. PSYCHIATRY 973 (1998). 
antisocial behavior, and alcohol and drug dependence. ${ }^{134}$ Men and woman both exhibit a similar pattern of genetic and environmental effects. ${ }^{135}$ Although there is significant genetic overlap among these disorders, genetic and environmental risk factors can be specific to each disorder. ${ }^{136}$ Large epidemiologic samples have identified a broad dimension of risk underlying antisocial personality disorder, conduct disorder, alcohol dependence, and drug dependence. ${ }^{137}$ This general vulnerability factor is typically referred to as "externalizing behavior problems," and recent twin studies have indicated that the source of the comorbidity in these disorders can be largely attributed to common genetic factors $\left(h^{2}=0.60-0.80\right.$, a broad sense estimate) ${ }^{138}$

\section{IV}

\section{UNPACKING THE GENETIC AND ENVIRONMENTAL BLACK BOXES}

Although the classical genetic studies of antisocial behavior have clearly demonstrated the importance of genetic predispositions as well as environmental influences, this research does not specify the precise biological or social mechanisms that underlie these global effects. Thus, both genetic and environmental influences represent "black boxes" in our understanding of antisocial behavior based on these classical studies. Unpacking these boxes is now a primary aim of much current research in this area. Several different approaches are being used to understand the biological and social mechanisms that underlie the genetic and environmental factors for antisocial behavior. These include: (1) a "measured risk factor" approach, in which multivariate genetic models are used to elucidate genetic mechanisms by studying various risk factors also known to be at least partially heritable and that are known to correlate with antisocial behavior; and (2) the "QTL approach," in which specific genes are identified and investigated for their associations and possible functional significance to antisocial behavior.

\section{A. Multivariate Genetic Models: The Measured Risk Factor Approach}

The "measured risk factor" approach investigates various traits and behaviors that are known to correlate with the risk of antisocial behavior in

134. Hicks et al., supra note 131, at 923; Kenneth S. Kendler et al., The Structure of Genetic and Environmental Risk Factors for Common Psychiatric and Substance Use Disorders in Men and Women, 60 ARCHIVES GEN. PSYCHIATRY 929 (2003); Robert F. Krueger et al., Etiologic Connections Among Substance Dependence, Antisocial Behavior, and Personality: Modeling the Externalizing Spectrum, 111 J. Abnormal Psychol. 411 (2002); Kristen C. Jacobson et al., Sex Differences in the Genetic and Environmental Influences on the Development of Antisocial Behavior, 14 DEV. \& PSYCHOPATHOLOGY 395 (2002).

135. Hicks et al., supra note 131, at 923; Kendler et al., supra note 134; Krueger et al., supra note 134; Jacobson et al., supra note 134.

136. See, e.g., Hicks et al., supra note 131, at 923; Kendler et al., supra note 134, at 929-30; Krueger et al., supra note 134, at 411-13; Jacobson et al., supra note 134.

137. See, e.g., Hicks et al., supra note 131, at 923.

138. Id. at 924-27. 
genetically informative designs, such as classical twin or adoption studies. Multivariate genetic models are thus used to explain sources of genetic covariance and environmental covariance that underlie these associations between risk-factors and antisocial behavior. ${ }^{139}$ This is similar to the "endophenotype approach," in which researchers identify highly heritable traits that show associations with antisocial behavior. ${ }^{140}$ In addition to estimating the components of genetic variance important to both antisocial behavior and the risk factor, multivariate models also compute the correlation between genes influencing antisocial behavior and genes influencing the risk factor or endophenotype. To the extent that a gene or set of genes may have manifold effects on both the risk factor and antisocial behavior (called pleiotropy), a large genetic correlation should result. A simple multivariate genetic model involving antisocial behavior and a single risk factor is presented in Figure 6, in which common genetic and environmental effects (A, C, and E) are shown to influence both the risk factor and antisocial behavior.

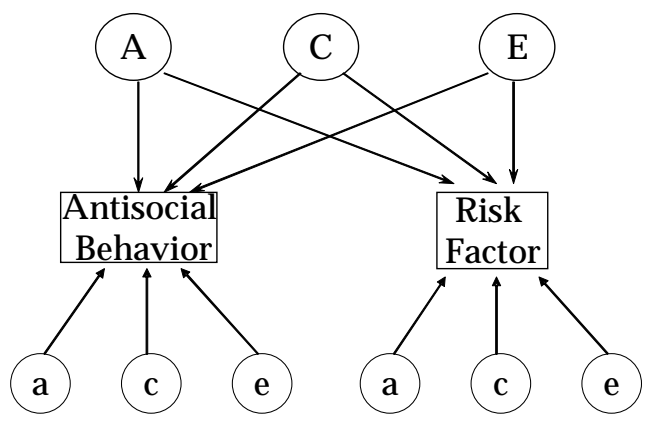

\section{Figure 6: Multivariate Genetic Model for Antisocial Behavior and a Measured Risk Factor (RF)}

To the extent that genes have pleiotropic effects, that is, to the extent that they influence more than one phenotype, common genetic influences on the risk factor and antisocial behavior should result. Close proximity- "genetic linkage" - of the genes influencing antisocial behavior to the risk factor, or certain patterns of assortative mating, such as antisocial individuals paired systematically to mates with extreme values of the risk factor, or both, can also contribute to the common genetic factors in Figure $6 .{ }^{141}$ Additional genetic influences that are specific to either antisocial behavior or the risk factor are

139. David M. Evans et al., Biometrical Genetics, 61 BiOlOGICAL PsYCHOL. 33, 45 (2002).

140. See generally Irving I. Gottesman \& Todd D. Gould, The Endophenotype Concept in Psychiatry: Etymology and Strategic Intentions, 160 AM. J. PSYCHIATRY 636 (2003).

141. D.S. FALCONER \& TRUdy F.C. MACKAY, InTROduction to QUANTITATIVE Genetics, 312-13 (4th ed. 1996). 
also indicated in this model (a, c, e effects for each phenotype). Thus, the total heritability for a given trait such as antisocial behavior may be parsed into components that are shared and not shared with the risk factor, in order to specify more exactly the nature of the global genetic influences in antisocial behavior.

Many of the various correlates of antisocial behavior reviewed earlier ${ }^{142}$ may be considered as possible endophenotypes, most notably personality traits such as impulsivity and attention deficits. A wide range of other characteristics showing associations with antisocial behavior has also been identified and includes both biological and social risk factors. ${ }^{143}$ Key biological risk factors include hormones, physiological (autonomic) underarousal, frontal lobe function (and dysfunction), and neurotransmitters. ${ }^{144}$ Any of these traits may be examined for common genetic relationships with antisocial behavior, although little work has been done using this approach to date.

One example of a biological risk factor for antisocial behavior is autonomic underarousal in antisocial-including violent-individuals. Antisocial individuals have shown a lower resting heart rate and lower electrodermal (that is, skin conductance) response, as well as smaller changes in these factors in response to novel stimuli such as auditory presentation of tones. ${ }^{145}$ The connections of these findings to antisocial behavior have been interpreted in several ways. For example, low heart rate may reflect fearlessness, or reduced anxiety ${ }^{146}$ lack of socialization, poor learning abilities due to cognitive deficits or emotional withdrawal or both, ${ }^{147}$ or reduced brain functioning in areas involved in mediating psychophysiological responding. ${ }^{148}$ Another explanation is that low arousal may lead to stimulation-seeking behaviors, including violence, in an attempt to raise autonomic arousal to optimal levels. ${ }^{149}$

142. See supra Part III.D.

143. See, e.g., Randy Borum, Assessing Violence Risk Among Youth, 56 J. ClinicAl PsyChOL. 1263, 1267-72 (2000).

144. See RAINE, supra note 124, at 40-46; Klaus A. Miczek et al., An Overview of Biological Influences on Violent Behavior, in 2 UNDERSTANDING AND PREVENTING VIOLENCE:

BiobehaVioral InFLUENCES 1 (Albert J. Reis et al. eds., 1994); DEBRA NiEHOFF, THE Biology of VIOLENCE 106-11, 115-49, 153-87 (describing brain imaging studies of violent offenders and explaining the "circular" relationship between hormones and behavior and between neurotransmitters and behavior) (1999); Laura A. Baker, Theories of Violence: Biology, in 3 VIOLENCE IN AMERICA 307, 307 (Ronald Gottesman \& Richard M. Brown eds., 1999).

145. See RAINE, supra note 124, at 160-65 (referring to findings of lower skin conductance in those who have committed crimes of evasion, and pointing to two of eight studies that found antisocial individuals to have lower skin-conductance responsivity to aversive tones); $i d$. at 166 (referring to findings of lower resting heart rates for "younger noninstitutionalized" antisocial individuals, but not for "institutionalized, criminal psychopaths"); id. at 173 (referring to the "virtually no anticipatory [heart rate] response" found in non-psychopathic criminals); id. at 185 (referring to findings of low heart rate, skin conductance, and response to novel stimuli in disinhibited children).

146. See David P. Farrington, The Relationship Between Low Resting Heart Rate and Violence, in Biosocial BASES OF ViOLENCE 89 (Adrian Raine et al. eds., 1997).

147. H.J. EYSENCK, CRIME AND PERSONALITY 80-104 (1977).

148. Raine et al., supra note 146, at 107-24.

149. EYSENCK, supra note 147 , at $80-104$. 
Although autonomic arousal in terms of heart rate and skin conductance has been shown to be at least partially heritable, ${ }^{150}$ it is unclear to what extent underarousal may be related to antisocial behavior due to a common genetic link. This question may be addressed using multivariate genetic analyses as indicated in Figure 6. In the USC twin study of nine- to ten-year-old children, multivariate analyses showed that a significant genetic correlation did in fact exist between heart rate and antisocial behavior. ${ }^{151}$ The heritable arousal factor, however, explained very little of the overall genetic variance in antisocial behavior in these children. ${ }^{152}$ Thus, the heritable component in antisocial behavior remains linked but largely independent of physiological underarousal.

Environmental mechanisms may also be investigated using the same "measured risk factor" approach in multivariate genetic models. As shown in Figure 6, the common and specific environmental influences for the risk factor and antisocial behavior may also be estimated. This approach may be used to help elucidate the nature of environmental influences important to antisocial behavior by determining, for example, the extent to which certain measured social risk factors and antisocial behavior may have correlated etiologies. Individual social risk factors that have been identified as being important to antisocial behavior include various aspects of parenting, such as harsh discipline and monitoring or awareness of children's activities and behaviors. ${ }^{153}$ These and other environmental factors, such as lead poisoning, ${ }^{154}$ need to be investigated in genetically informative designs to determine the extent to which their effects may be moderated by individual genetic predispositions.

\section{B. Identifying Specific Genes for Antisocial Behavior: The Quantitative Trait Loci Approach}

A second approach for unpacking the genetic black box involves QTL designs, in which specific genes are identified as having either associations with or functional significance in antisocial behavior. These studies also help inform us about environmental influences, in that measured environmental factors can be used to understand the circumstances under which genes for antisocial behavior become expressed. The QTL methods may be considered a measured gene approach.

Although family and twin studies have shed light on the critical role of genetics in antisocial behavior, certain negative outcomes can be most effectively treated and prevented by understanding the precise mechanisms

150. Andrew Crider et al., Stability, Consistency, and Heritability of Electrodermal Response Lability in Middle-Aged Male Twins, 41 PsYCHOPHYSIOLOGY 501, 502 (2004).

151. See K.C. Jacobson et al., Abstract, Genetic Mediation of the Relationship between Arousal and Antisocial Behavior in Pre-Adolescent Twins, 35 BEHAV. GENETICs 832a, 832a (2005).

152. Id.

153. See Borum, supra note 143, at 1271.

154. See Kim N. Dietrich et al., Early Exposure to Lead and Juvenile Delinquency, 23 Neurotoxicology \& Teratology 511 (2001); Herbert L. Needleman et al., Bone Lead Levels and Delinquent Behavior, 275 JAMA 363 (1996). 
involved in the pathways from genes to behavior. This understanding can be greatly enhanced by identifying which genes are involved in antisocial behavior. Despite popular belief, genetic traits are not immutable. Although individual genes themselves cannot be easily altered, knowing which genes are involved in behavioral disorders such as antisocial behavior, ADHD, oppositional defiant disorder, and conduct disorder leads to a better understanding of the underlying mechanisms and biological underpinnings of a gene.

For instance, identifying particular genes that might be associated with certain disorders and that regulate neurotransmitter activity might enable adjustment of neurotransmitter levels and functions accordingly by pharmacological or environmental methods. "Neurotransmitters are brain chemicals that transmit messages from cell to cell, enabling neural [communication]. Neurotransmitter metabolism and receptor function are crucial for most of the brain's functions, including mood, behavior, [and] emotion ...."155 In the case of antisocial behavior, several neurotransmitters associated with genes have been identified, including serotonin, and dopamine. These neurotransmitters or neurochemicals are highly sensitive to environmental manipulations. ${ }^{156}$

Among the neurochemicals examined over the past three decades for their relationship to antisocial behavior, none has been scrutinized so intensely as serotonin (5-hydroxytryptamine, or 5-HT). ${ }^{157}$ Although the psychological mechanism underlying this relationship remains unclear, some research models speculate that low levels of serotonin increase impulsivity and inhibit sensible behavior and therefore increase the likelihood of risky and antisocial behavior. ${ }^{158}$ Thus, deficiencies in serotonin have been linked with several types of impulsive behavior, including drug abuse, antisocial personality disorder, and gambling. ${ }^{159}$ In particular, the "[1] evel of brain serotonergic activity appears to have a profound influence on the production of impulsive-aggressive behavior. In [laboratory studies conducted on] rats, lesions of the septal area and other structures dense with serotonergic connections produce rage and attack [behaviors]." Moreover, "one of the most widely reproduced findings in neuropsychiatry is that indicators of serotonin activity are lower in humans characterized as impulsive and violent towards themselves and others. ${ }^{" 160}$

155. Goldman \& Fishbein, supra note 89, at 9-4.

156. David E. Comings, The Role of Genetics in ADHD and Conduct Disorder-Relevance to the Treatment of Recidivist Antisocial Behavior, in THE SCIENCE, TREATMENT, AND PREVENTION OF ANTISOCIAL BEHAVIORS: APPLICATION TO THE CRIMINAL JUSTICE SYSTEM, supra note 70, at 16-1.

157. Todd M. Moore et al., A Meta-Analysis of Serotonin Metabolite 5-HIAA and Antisocial Behavior, 28 AGGRESSIVE BEHAV. 299 (2002).

158. Id. at 300 .

159. Scott D. Lane \& Don R Cherek, Biological and Behavioral Investigation of Aggression and Impulsivity, in THE SCIENCE, TREATMENT, AND PREVENTION OF ANTISOCIAL BEHAVIORS: APPLICATION TO THE CRIMINAL JUSTICE SYSTEM, supra note 70, at 5-1.

160. Marie Åsberg et al., Psychobiology of Suicide, Impulsivity, and Related Phenomena, in PSYCHOPHARMACOLOGY: THE THIRD GENERATION OF PROGRESS 655, 657-58 (Herbert Y. Meltzer ed., 1987); Alex Roy et al., Serotonin in Suicide, Violence, and Alcoholism, in SEROTONIN IN MAJOR 
Therefore, "deficits in brain serotonergic activity produce behavioral disinhibition, resulting in an increased likelihood of impulsive aggressiveness or other excessive and inappropriate behavior.,"161

In addition, specific 5-HT genes have also been identified in association with aggressive and violent behavior; these genes are particularly good candidates for conduct disorder and aggressive behavior. ${ }^{162}$ For example, very aggressive behavior has been observed in mice in which the $\mathrm{HTR}_{1 \mathrm{~B}}$ gene has been functionally removed. ${ }^{163}$ Similarly, in humans the "5- $\mathrm{HT}_{1 \mathrm{~B}}$ gene has been localized to chromosome 6." ${ }^{164}$ In subjects with antisocial personality disorder, a decrease in the frequency of a polymorphism (a variant form) of the 5- $\mathrm{HT}_{1 \mathrm{~B}}$ gene has been found as compared to normal controls. ${ }^{165}$

A second serotonergic gene showing relationships to antisocial behavior is the $\mathrm{HTR}_{2 \mathrm{~A}}$ gene. A variant polymorphism of this gene, the serotonin ${ }_{2 \mathrm{~A}}$ receptor gene, was examined in a sample of Caucasian substance abusers and age- and ethnically matched controls. ${ }^{166}$ The results demonstrated that this gene was associated with the amount of money spent on drugs, histories of shoplifting, vandalism, or rape, and elevated scores on assault and hostility scales. ${ }^{167}$

A third serotonergic gene associated with antisocial behavior is the $\mathrm{HTR}_{1 \mathrm{DA}}$ gene, which is purported to play a role in 5-HT metabolism. ${ }^{168}$ The $\mathrm{C}$ variant of this gene was found to be significantly more common in adult offenders with antisocial personality disorder and in childhood conduct disorder than in normal controls. ${ }^{169}$

The last 5-HT gene associated with antisocial behavior is the TDO2 (tryptophan 2,3-dioxydase) gene. Tryptophan is a known precursor of 5-HT. ${ }^{170}$ Increased activity of TDO2 is associated with low levels of 5-HT and in turn

PSYCHIATRIC DisORDERS 185, 187-89 (Emil F. Coccaro \& Dennis L. Murphy eds., 1990); Matti Virkkunen et al., Relationship of Psychobiological Variables to Recidivism in Violent Offenders and Impulsive Fire Setters, 46 ARCHIVES GEN. PSYCHIATRY 600, 600-01 (1989).

161. Goldman \& Fishbein, supra note 89, at 9-9. See also Oliver Cases et al., Aggressive Behavior and Altered Amounts of Brain Serotonin and Norepinephrine in Mice Lacking MAOA, 268 SCIENCE 1763 (1995).

162. $\mathrm{HTR}_{1 \mathrm{~B}}, \mathrm{HTR}_{2 \mathrm{~A}}$, and $\mathrm{HTR}_{1 \mathrm{DA}}$ denote serotonin receptor genes, which influence the function of serotonin. Some or most of these genes may have variants. Each gene receptor may be localized to a specific chromosome and perform a different and/or particular function.

163. Frederic Saudou et al., Enhanced Aggressive Behavior in Mice Lacking 5-HT ${ }_{1 B}$ Receptor, 265 SCIENCE 1875 (1994).

164. Comings, supra note 156, at 16-9. See also Matti Virkkunen et al., Serotonin in Alcoholic Violent Offenders, in GENETICS OF CRIMINAL AND ANTISOCIAL BEHAVIOR, supra note 55, at 168.

165. Id.

166. Id.

167. Id. at $16-9$ to $16-10$.

168. Richard A Glennon \& Malgorzata Dukat, Serotonin Receptor Subtypes, in Psychopharmacology: The Fourth Generation of Progress 415, 421 (Floyd E. Bloom \& David J. Kupfer eds., 1995).

169. Comings, supra note 156, at 16-10.

170. Id.; see also P.S. Timiras et al., Lifetime Brain Serotonin: Regional Effects of Age and Precursor Availability, 5 NeUROBIOLOGY OF AGING 235, 236-37 (1984) (studying the effects of reducing serotonin by reducing the amount of its precursors, including tryptophan). 
associated with aggressive behaviors. ${ }^{171}$ Several identified genetic polymorphisms of this gene were found to be associated with alcoholism, drug abuse, ADHD, and Tourette's syndrome. ${ }^{172}$

Additionally, sociocultural factors such as socioeconomic status, stress, and nutrition may play a role in the relationship between neurotransmitters and behavior. ${ }^{173}$ For example, diets low in or otherwise blocking the uptake of tryptophan (a dietary precursor of serotonin) have been found to lower levels of serotonin in the brain from which they never fully recover, even after returning to a normal diet. ${ }^{174}$

Dopamine is another major neurotransmitter considered to play a role in behavioral activation, reward mechanisms, and goal-directed behaviors. Results from animal studies indicate that increased dopamine functioning is usually associated with increases in defensive aggression. ${ }^{175}$ It has also been suggested that dopamine activity may be positively associated with aggressive or impulsive behavior in humans. ${ }^{176}$ Results of central neurochemical studies of humans, however, parallel those of serotonin studies, indicating that dopamine activity is inversely correlated with aggressive behavior. ${ }^{177}$ For example, cerebrospinal fluid homovanillac acid, a dopamine metabolite, has been found to be negatively correlated with a life history of aggression. ${ }^{178}$ In addition, low levels of cerebrospinal fluid homovanillac acid appear to discriminate recidivist violent criminal offenders from nonrecidivists and incarcerated offenders with antisocial personality disorder from those with paranoid or passive-aggressive personality disorders. ${ }^{179}$

The DRD2 gene, a specific dopamine receptor gene, has been positively linked not only to ADHD, but also to a range of impulsive, compulsive, and addictive behaviors. ${ }^{180}$ The prevalence of a particular gene variant of DRD2 (the Taq A1 allele) has been studied in a range of disorders. ${ }^{181}$ In addition to its

171. Comings, supra note 156, at 16-10.

172. Id.; David E. Comings et al., Polygenic Inheritance of Tourette Syndrome, Stuttering, Attention Deficit Hyperactivity, Conduct, and Oppositional Defiant Disorder: The Additive and Subtractive Effect of the Three Dopaminergic Genes-DRD2, D H, and DAT1, 67 AM. J. MED. GENETICs 264 (1996).

173. Moore et al., supra note 157 , at 313.

174. Id.

175. See, e.g., Petra Netter \& Thomas Rammsayer, Reactivity to Dopaminergic Drugs and Aggression Related Personality Traits, 12 PERSONALITY \& INDIVIDUAL DIFFERENCES 1009 (1991); Michael R. Spoont, Modulatory Role of Serotonin in Neural Information Processing: Implications for Human Psychopathology, 112 PSYCHOL. BULL. 330 (1992).

176. Graham Rogeness et al., Neurochemistry and Child and Adolescent Psychiatry, 31 J. AM. ACAD. CHILD \& ADOLESCENT PSYCHIATRY 765, 775-77 (1992).

177. Mitchell E. Berman et al., Neurotransmitter Correlates of Human Aggression, in HANDBOOK OF ANTISOCIAL BEHAVIOR, supra note 60, at 305, 310.

178. See, e.g., Rhona Limson et al., Personality and Cerebrospinal Fluid Monoamine Metabolites in Alcoholics and Controls, 48 ARCHIVES GEN. PSYCHIATRY 437, 439 (1991).

179. See Berman et al., supra note 177 , at 305.

180. Comings, supra note 156, at 16-6.

181. Id.; see also Comings et al., supra note 172 (examining the relationship between the gene variant to such disorders as Tourette's syndrome, stuttering, and ADHD). 
link with disorders such as ADHD, the A1 allele was also significantly elevated in conduct disorder, post traumatic stress disorder, alcoholism, and drug abuse. $^{182}$ This gene was also examined as potentially related to violent behavior. ${ }^{183}$ The results indicated that those who carried the A1 allele were significantly more likely to have engaged in fighting behavior in school and to be incarcerated for violent crimes as adults. ${ }^{184}$ Thus these findings indicate that the DRD2 gene may be one of the genes involved in aggressive behavioral disorders. $^{185}$

Monoamine oxidase (MAO) A and B are two enzymes that metabolize dopamine, norephinephrine, and serotonin. ${ }^{186}$ MAO activity has been utilized as an index of central presynaptic serotonergic functioning in impulsive and aggressive individuals. ${ }^{187}$ When MAO levels are low, these neurotransmitters become imbalanced. Abnormally low levels in MAO have been linked with a wide range of disorders, including ADHD, alcoholism, drug abuse, and impulsive and risk-taking behaviors. ${ }^{188}$

Significant associations have been found between longer base pair alleles of the MAOA gene, an X-chromosome gene, and various behavior disorders, including ADHD, conduct disorder, major depressive disorder, drug abuse, alcoholism, and learning disabilities. ${ }^{189}$ Furthermore, genetic deficiencies in MAOA have been linked with aggression in mice and in humans. ${ }^{190}$ In the Brunner study of MAOA deficiencies in a Dutch family sample, a null allele at the MAOA locus was associated with antisocial behavior in males. ${ }^{191}$

\section{$\mathrm{V}$ \\ MODELS OF COMPLEX INTERACTIONS IN ANTISOCIAL BEHAVIOR}

Genetic influences in antisocial behavior-even if specified at the level of DNA - are by no means simple. As in many other phenotypes, gene expression for antisocial behavior may well depend on a variety of other factors, including

182. Comings, supra note 156 , at $16-6$.

183. Id. at $16-6$ to $16-7$.

184. Id.

185. Id. at $16-11$ to $16-12$.

186. $I d$.

187. Berman et al., supra note 179 , at 307 .

188. Eric J. Devor et al., Association of Monoamine Oxidase (MAO) Activity with Alcoholism and Alcoholic Subtypes, 48 AM. J. MED. GeNETICs 209 (1993); Anne-Liis Von Knorring et al., Platelet Monoamine Oxidase Activity in Type 1and Type 2 Alcoholism, 26 Alcohol \& AlCOHOLISM 409 (1991); Walid O. Shekim et al., Platelet MAO Activity and Personality Variations in Normals, 27 PSYCHIATRY RES. 81 (1989); Monte S. Buchsbaum et al., The Biochemical High-Risk Paradigm: Behavioral and Familial Correlates of Low Platelet Monoamine Oxidase Activity, 194 SCIENCE 339 (1976); C.G. Gottfries et al., Lowered Monoamine Oxidase Activity in Brains from Alcoholic Suicides, 25 J. NEUROCHEMISTRY 667 (1975).

189. See Comings, supra note 156 , at $16-11$ to $16-12$.

190. J.C. Shih et al., Monoamine Oxidase: From Genes to Behavior, 22 AnN. REV. NeURosCIENCE 197, 210 (1999).

191. H.G. Brunner et al., Abnormal Behavior Associated with a Point Mutation in the Structural Gene for Monoamine Oxidase A, 262 SCIENCE 578 (1993). 
the effects of other genes as well as numerous environmental circumstances. Several classical genetic studies have provided strong evidence for interactions between genes and environment, and these effects have also begun to emerge in QTL studies examining specific genes and more narrowly specified environments. Outside of genetically informative studies, there is also a growing acceptance of more comprehensive models that encompass both biological and social risk factors for antisocial behavior, as well as their interactions.

\section{A. Gene X Environment Interactions}

The extent to which genetic effects vary as a function of environmental factors is referred to as a gene $\mathrm{X}$ environment $(\mathrm{GxE})$ interaction. ${ }^{192}$ A statistical GxE interaction has been consistently found in all major adoption studies of criminal convictions, such that the genetic predispositions, indicated by biological-parent antisocial behavior, present the greatest risk to the adopted offspring in the presence of adverse environmental conditions, indicated by adoptive-parent antisocial behavior. Figure 7 provides an illustrative example of a GxE interaction in criminality identified in a Danish adoption study. ${ }^{133}$

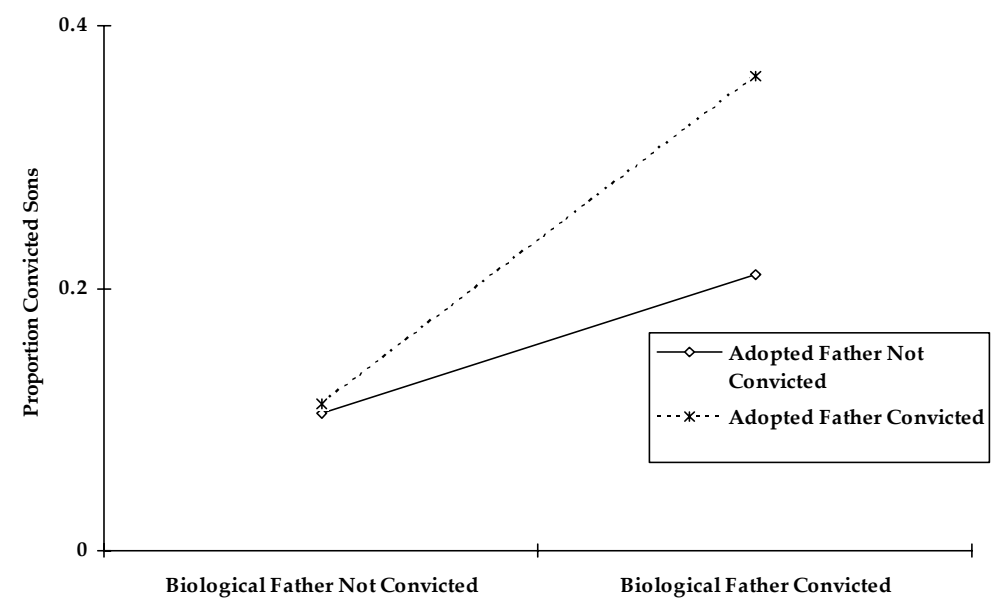

Adapted from Hutchings \& Mednick, supra note 38

\section{Figure 7: Property Crime Convictions in Danish Adopted Sons and Their Fathers}

192. This is a statistical interaction, which is distinct from the general notion that both genes and environment may combine together to produce phenotypic outcomes.

193. Sarnoff A. Mednick et al., Genetic Influences in Criminal Convictions: Evidence from an Adoption Cohort, 224 SCIENCE 891 (1984). 
As shown here, the property-crime conviction rate in adopted sons is significantly higher for those with a biological father previously convicted of a property offense, both in families with and without a convicted adoptive father. ${ }^{194}$ This increase in the conviction rate is greatest, however, when the adoptive father had also been convicted. ${ }^{195}$ In other words, negative environmental factors stemming from being raised by antisocial parents may exert their greatest effects on individuals who are genetically predisposed towards antisocial behavior. ${ }^{196}$ A remarkably similar pattern of results has been found in adoption studies in both Scandinavia ${ }^{197}$ and the United States. ${ }^{198}$

More recently, this global GxE interaction has begun to be seen at the specific gene level. In particular, a deleterious MAOA gene, which has been linked to aggression in both humans ${ }^{199}$ and mice, ${ }^{200}$ has been demonstrated to have the greatest influence on violence and other antisocial outcomes in individuals who have experienced severe maltreatment (including physical abuse) during childhood. ${ }^{201}$ As other specific genes are more clearly identified and replicated, specific environmental factors may be shown to moderate their effects.

These results also have profound implications for our understanding of the role of parents and of other environmental aspects in producing aggressive and other antisocial outcomes in children. At the very least, the findings of $\mathrm{GxE}$ interactions in antisocial behavior highlight the complexity of gene-behavior relationships. Even when strong genetic effects are found, these may be enhanced or reduced by a variety of factors.

B. Biosocial Model of Antisocial Behavior

Over the past fifty years, important progress has been made in delineating replicable psychosocial risk factors for antisocial and violent behavior. ${ }^{202}$ Within the past fifteen years, important progress has also been made in uncovering

194. $I d$.

195. $I d$.

196. Id.

197. See Cloninger \& Gottesman, supra note 38.

198. See Cadoret et al., supra note 58.

199. See Brunner et al., supra note 191.

200. Shih et al., supra note 190.

201. See Caspi et al., Role of Genotype in the Cycle of Violence in Maltreated Children, 297 SCIENCE 851 (2002).

202. See, e.g., Michael Rutter et al., Antisocial Behavior by Young People (1998); David P. Farrington, Psychosocial Predictors of Adult Antisocial Personality and Adult Convictions, 18 BehAV. SCI. \& L. 605 (2000); Stephen P. Hinshaw \& Carolyn A. Anderson, Conduct and Oppositional Defiant Disorders, in CHILD PsyChOPATHOLOGY 113 (Eric J. Marsh \& Russell A. Barkley eds., 1996); Rolf Loeber \& David P. Farrington, Never Too Early, Never Too Late: Risk Factors and Successful Interventions for Serious and Violent Juvenile Offenders, 7 STUD. ON CRIME \& CRIME PREVENTION 7 (1998); Joan McCord, Psychosocial Contributions to Psychopathy and Violence, in VIOLENCE AND PSYCHOPATHY 141 (Adrian Raine \& José Sanmartín eds., 2001). 
biological risk factors that predispose individuals to antisocial behavior. ${ }^{203}$ Despite this progress, until recently we have learned surprisingly little about how these different sets of risk factors interact in predisposing individuals to antisocial behavior. Furthermore, even though heuristic and theoretical references are frequently, if incidentally, made to such interactive influences, remarkably few investigators have conducted serious empirical research on this interface in humans. ${ }^{204}$

Very recently, however, there has been renewed interest in biosocial interaction effects. In this context, Figure 8 depicts a heuristic biosocial model that emphasizes the importance of risk and protective factors, the interaction of social and biological variables, and different forms of antisocial behavior. A key conceptual issue is the assumption that joint assessment of both social and biological factors is a critical interdisciplinary approach that will yield innovative insights into the development of antisocial behavior. In the following section, broad processes are outlined to accommodate the many constructs that biosocial researchers use and to allow some degree of specificity and testability.

203. See, e.g., Rutter et al., supra note 202; Benjamin B. Lahey et al., Psychobiology, in Conduct Disorders IN CHILDREN AND AdOLESCENTS 27 (G. Pirooz Sholevar ed., 1995); Terrie E. Moffitt, The Neuropsychology of Juvenile Delinquency: A Critical Review, 12 CRIME \& JUST. 99 (1990); Elizabeth J. Susman \& Jordan W. Finkelstein, Biology, Development, and Dangerousness, in CLINICAL ASSESSMENT OF DANGEROUSNESS 23 (Georges-Frank Pinard \& Linda Pagani eds., 2001).

204. See Raine et al., Biosocial Bases of Violence: Conceptual and Theoretical Issues, in BIOSOCIAL BASES OF VIOlENCE 1 (Adrian Raine, Patricia A. Brennan, David P. Farrington, \& Sarnoff A. Mednick, eds. 1997). 


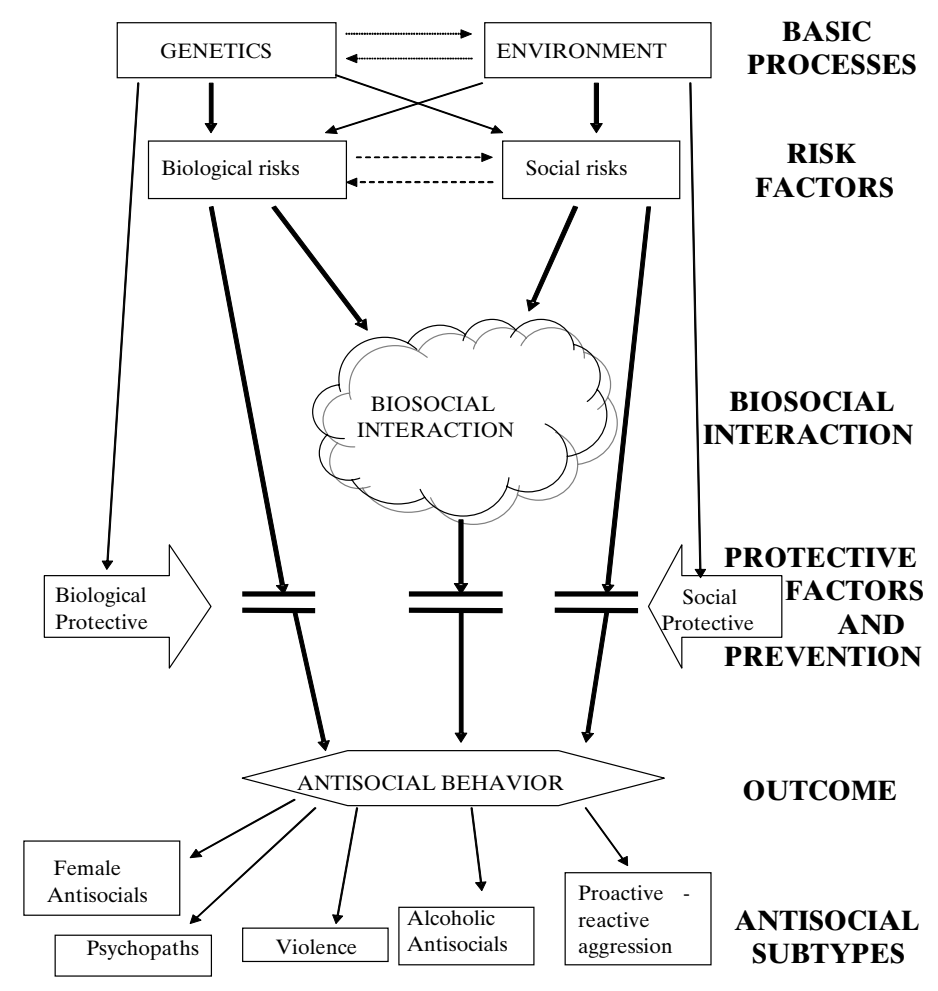

Figure 8: Biosocial Model of Antisocial Behavior

1. The Biosocial Model

The right side of the figure outlines the key processes in the model. From top to bottom, they are as follows:

(1) Genes and environment as determinants of risk and protective factors: Both forces are assumed to be the building blocks for later processes, and each may directly influence both sets of risk factors (solid straight and crossed arrows from "genetics" and "environment" to "biological risks" and "social risks"), as well as protective factors. The model also suggests, however, that these forces may interact (dotted arrows connecting "genetics" and "environment"); environmental forces can give rise to the expression of a latent genetic trait and vice-versa.

(2) Reciprocal relationships between biological and social risk factors: Biological and social risk factors may have reciprocal relationships, as indicated by broken lines connecting "biological risks" and "social risks." For example, the social risk factors of early life stress or negative parenting may mitigate the biological risk factor of autonomic activity. 
(3) Biological and social risk factors-direct pathways: Biological risk factors may directly result in antisocial behavior independently of social risk factors and vice-versa (solid lines from "biological risks" and "social risks" to "antisocial behavior"). The vast majority of research to date assumes these direct effect pathways.

(4) Biosocial interactions: The much less tested proposition is that biological and social risk factors interact to produce antisocial behavior (solid lines from "biological risks" and "social risks" to "biosocial interaction"). This is the crux of the model and is elaborated on further below.

(5) Protective factors and prevention: Importantly, biological and social protective factors (and preventive programs) can break all three pathways (biological, social, and biosocial) to antisocial behavior (interruption of lines from "biosocial interaction" to "antisocial behavior" by protective factors).

(6) Antisocial subtypes: Risk factors give rise to both a general predisposition to antisocial behavior and several different antisocial subtypes with potentially different etiological bases, such as psychopathy or violence.

\section{Examples of Biosocial Interactions}

If genetic factors interact with the environment in predisposing individuals to antisocial behavior, it is incumbent on researchers to identify the specific biological factors that interact with the specific environmental processes in giving rise to such behavior. A recent review of this literature identified thirtynine empirical examples of biosocial interaction effects for antisocial behavior from the areas of genetics, psychophysiology, obstetrics, brain imaging, neuropsychology, neurology, hormones, neurotransmitters, and environmental toxins. ${ }^{205}$ Two main themes emerged. First, when biological and social factors are grouping variables and when antisocial behavior is the outcome, then the presence of both risk factors exponentially increases the rates of antisocial and violent behavior. ${ }^{206}$ Second, when social and antisocial variables are grouping variables and biological functioning is the outcome, then invariably the social variable moderates the antisocial-biology relationship such that these relationships are strongest in those from benign home backgrounds. ${ }^{207}$

With respect to the first theme, several studies have shown that babies who suffer birth complications are more likely to develop conduct disorder and

205. See Adrian Raine, Biosocial Studies of Antisocial and Violent Behavior in Children and Adults: A Review, 30 J. ABNORMAL CHILd PsyChOL. 311 (2002).

206. Id. at 323 .

207. Id. 
delinquency, commit impulsive crime, and act violently in adulthood when other psychosocial risk factors are present. Specifically, obstetric factors interact with psychosocial risk factors in relation to adult violence. Birth complications have been found to interact with a disruptive family environment, characterized by maternal separation, illegitimacy, marital discord, parental mental health problems, or paternal absence in predisposing individuals to delinquency. ${ }^{208}$ In 4,269 live male births in Denmark, similar results were obtained in a prospective assessment of birth complications and maternal rejection at the age of one. ${ }^{209}$ Birth complications significantly interacted with maternal rejection of the child in predicting violent offending at the age of eighteen. ${ }^{210}$ Four percent of the sample had both birth complications and maternal rejection, but this small group accounted for $18 \%$ of all the violent crimes committed by the entire sample. ${ }^{211}$ This finding from Denmark has recently been replicated in four other countries in the context of a variety of psychosocial risk factors and consequently appears robust. ${ }^{212}$

With respect to the second theme, previous research has indicated that violent offenders have reduced functioning of the prefrontal cortex. ${ }^{213}$ One positron emission topography (PET) study addressed how psychosocial deficits moderate the relationship between prefrontal dysfunction and violence. ${ }^{214} \mathrm{~A}$ sample of murderers was divided into those who came from relatively good home backgrounds and those who came from relatively bad ones, as defined in the study. Ratings of psychosocial deprivation took into account early physical and sexual abuse, neglect, extreme poverty, foster home placement, having a

208. Emmy E. Werner, Vulnerability and Resiliency in Children at Risk for Delinquency: A Longitudinal Study from Birth to Young Adulthood, in 10 PREVENTION OF DELINQUENT BEHAVIOR 16, 22-28 (John D. Burchard \& Sara N. Burchard eds., 1987, vol. 10 of PRIMARY PREVENTION OF PSYCHOPATHOLOGY).

209. Adrian Raine et al., Birth Complications Combined with Early Maternal Rejection at Age 1 Year Predispose to Violent Crime at Age 18 Years, 51 ARCHIVES GEN. PSYCHIATRY 984, 984 (1994).

210. $I d$.

211. $I d$.

212. Sheilagh Hodgins et al., Obstetric Complications, Parenting, and Risk of Criminal Behavior, 58 ARCHIVES GEN. PSYCHIATRY 746 (2001) (finding pregnancy complications interacted with poor parenting in predicting adult violence in a large Swedish sample); Liisa Kemppainen et al., The OneChild Family and Violent Criminality: A 31-Year Follow-Up Study of the Northern Finland 1966 Birth Cohort, 158 AM. J. PSYCHIATRY 960 (2001) (finding that perinatal risk interacted with being an only child in raising the odds of adult violent offending by a factor of 4.4 in a sample of 5,587 Finnish males); Louise Arseneault et al., Obstetrical Complications and Violent Delinquency: Testing Two Developmental Pathways, 73 CHILD DEV. 496 (2002) (finding in Canada that serious birth complications interacted with an adverse family environment in predisposing to violence at ages 6 and 17 and that this effect accounted for the continuity in violence between these ages); Alex Piquero \& Stephen Tibbetts, The Impact of Pre/Perinatal Disturbances and Disadvantaged Familial Environment in Predicting Criminal Offending, 8 STUD. ON CRIME \& CRIME PREVENTION 52 (1999) (finding in a prospective longitudinal study of 867 males and females from the Philadelphia Collaborative Perinatal Project that those with both pre/perinatal disturbances and a disadvantaged familial environment were much more likely to become adult violent offenders).

213. Nora D. Volkow et al., Brain Glucose Metabolism in Violent Psychiatric Patients: A Preliminary Study, 61 Psychiatry ReS.: NeUROIMAgING 243 (1995).

214. Adrian Raine et al., Prefrontal Glucose Deficits in Murderers Lacking Psychosocial Deprivation, 11 NeUROPSYCHIATRY, NEUROPSYCHOLOGY \& BEHAV. DisORDERS 1 (1998). 
criminal parent, severe family conflict, and a broken home. Compared to normal controls, deprived murderers showed relatively good prefrontal functioning, while nondeprived murderers showed significantly reduced prefrontal functioning. ${ }^{215}$ In particular, murderers from good homes had a $14.2 \%$ reduction in the functioning of the right orbitofrontal cortex; damage to this brain area results in reduced fear conditioning as well as personality and emotional deficits that parallel criminal psychopathic behavior ${ }^{216}$ or what some have termed "acquired sociopathy." ${ }^{217}$ These results extend findings from several psychophysiological studies showing especially reduced autonomic functions in those from benign home backgrounds and again suggest that biology-violence relationships are potentiated in those lacking psychosocial risk factors for violence.

\section{VI \\ CONCLUSION}

Genetic influences are clearly important in antisocial behavior, including criminality. Numerous classical twin and adoption studies, as well as more recent studies of specific genes, support this conclusion. Heritability estimates suggest as much as one-half of the variation in propensity toward antisocial behavior can be explained by genetic differences among individuals. Moreover, various traits correlated with antisocial behavior appear heritable, including impulsivity, autonomic arousal, and attention and other cognitive deficits. Although some specific genes for antisocial behavior have been suggested by QTL studies, the global genetic influence indicated by the moderate heritability estimate remains largely unspecified. Several biological risk factors have also been identified, although the extent to which their relationships to antisocial behavior may be genetically mediated remains unknown.

Genetic research, however, also makes a strong case for the importance of environment in influencing antisocial behavior. In fact, the more we know about genetics of behavior, the more important the environment appears to be. Heritability estimates are far from agreement, leaving much room for environmental variations to influence antisocial outcomes. Most importantly, the environment itself appears to play a critical role in the expression and magnitude of genetic influences in antisocial behavior, as evidenced by the wellreplicated findings of $\mathrm{GxE}$ interactions in several adoption studies, as well as more recent studies of specific genes such as MAO. ${ }^{218}$

What does heritability of antisocial behavior imply for individuals? Very little. Heritability estimates provide information about individual differences in

215. Id.

216. Id. at 5-6.

217. Jeffrey L. Saver \& Antonio R. Damasio, Preserved Access and Processing of Social Knowledge in a Patient with Acquired Sociopathy Due to Ventromedial Frontal Damage, 29 NEUOROPSYCHOLOGIA 1241 (1991).

218. See Caspi et al., supra note 210, at 851. 
behavior within a group of individuals, and these estimates are specific to historical time, age cohort, and the given culture from which the sample is drawn. Even within the population, heritability is merely a statistical description of variance within that particular group, and it has little or no predictive value for any one individual. That is, when risk rates for criminality might be computed for groups of individuals, such as the relatives of a convicted felon, errors in prediction for a given individual would be quite large. Heritability estimates do not provide any information about one individual's DNA or genetic risk and thus cannot be used to understand one person's behavior or risk for future behavior.

Unlike heritability estimates from classical genetic designs, however, QTL studies do provide more detailed information at an individual level. As more specific genes are shown to play a role in the risk for antisocial behavior, predictions of individual behavior could become increasingly accurate. Still, genes rarely, if ever, operate deterministically such that a given behavior can be predicted with any reasonable degree of certainty. Although individual genes can be more highly predictive of individual behavior, there will always be large errors in prediction. Moreover, the effects of specific genes can often be modified through environmental interventions. Such interventions have already proven to be feasible even for highly heritable traits, such as phenylketonuria (PKU), a single-gene disorder resulting in mental retardation, which can be ameliorated by omitting phenylanine from the diet. This point is underscored by the GxE interactions for antisocial behavior as well as the biosocial model, both of which emphasize the moderating effects of social factors on biological risks for antisocial behavior.

In spite of our increasing ability to identify specific genes important to antisocial behavior - and to identify individuals who inherit high risk genesour ability to understand and predict any one individual's behavior is still far from perfect and will probably remain so indefinitely. Specific genes that show associations with complex traits are likely to have small effects on risk partly because of the moderating effects of other genes as well as environmental factors. Although genes may increase propensity for criminality, for example, they do not determine it - the preponderance of individuals with the same gene are likely not to have engaged in serious antisocial behavior.

The wide variation in behavior observed for individuals sharing the same gene or set of genes (recall that MZ correlations for antisocial behavior or concordance for conduct disorder or antisocial personality disorder are far from agreement) is further evidence that genes do not operate in any deterministic way. Given this lack of genetic determinism, behavioral genetic research does not provide a sufficient basis for arguing against the notion of individual responsibility for one's behavior.

The genetic and environmental influences in antisocial behavior themselves still remain as large "black boxes." Understanding the genetic and social mechanisms underlying antisocial behavior is still in its infancy. These 
mechanisms are likely to be clarified over the next few decades, however, with increasing numbers of QTL studies in this area. As understanding the root causes of antisocial behavior increases, we may be optimistic that a more therapeutic approach will emerge for treating individuals who engage in or appear to be at risk for antisocial behavior. 